\title{
Analysis of a Train-operating Company's Customer Service System during Disruptions: Conceptual Requirements for Gamifying Frontline Staff Development
}

Ben Clegg, Richard Orme, Chris Owen, Pavel Albores

\section{Abstract}

This paper provides an account of an action research study into the systemic success factors which help frontline staff react to and recover from a rail service disruption. This study focuses on the effective use of information during a disruption to improve customer service, as this is a priority area for train-operating companies (TOCs) in Great Britain.

A novel type of systems thinking, known as Process-Oriented Holonic Modelling (PrOH), has been used to investigate and model the 'Passenger Information During Disruption' (PIDD) system.

This paper presents conceptual requirements for a gamified learning environment; it describes 'what'; 'how' and 'when' these systemic success factors could be gamified using a popular disruption management reference framework known as the Mitigate, Prepare, React and Recover (MPRR) framework.

This paper will interest managers of and researchers into customer service system disruptions, as well as those wishing to develop new gamified learning environments to improve customer service systems.

Keywords: customer service systems; gamification; systems thinking; Mitigate-PlanReact-Recovery (MPRR) framework; disruption management; frontline staff training 


\section{BACKGROUND}

The number of rail journeys across Great Britain's (GB's) rail network hit a recordbreaking 1.65 billion in 2014-15 (Rail Delivery Group, 2015). The network has become increasingly overcrowded and, for decades, has been perceived by its users as lagging behind the performance of those in other leading national economies (DfT, 2004). In light of this and with increasing dissatisfaction by passengers in Great Britain, the GB's Rail Technology Strategy (RTS) stated that the management system for 'Passenger Information During Disruption' (PIDD) had to be significantly improved (RSSB and TSLG, 2012). Similarly, the Passenger Focus 2014 report revealed that three of the top twelve rail passengers' improvement priorities directly related to information use during disruptions: "train companies [need to] keep passengers informed about delays" $\left(5^{\text {th }}\right)$, "accurate and timelier information [must be] available at stations" $\left(8^{\text {th }}\right)$, and "accurate and timelier information [must be] provided on trains" $\left(12^{\text {th }}\right)$ (Passenger Focus, 2014). Disruptions cause the re-planning of services and can last from hours to days (Pender, 2012).

On a more positive note, the processes, procedures and information systems for planning tactical or operational services during normal periods of service operation are, on the whole, considered as coping adequately, but, during disruptions, the systems, channels of communication, decision makers and fora for decision-making often become quickly overloaded and currently lack the ability to characterise disruptions accurately enough and reschedule services quickly enough (Narayanaswami and Rangaraj, 2012). This is because normal planning systems struggle to react to ever-changing operational characteristics such as the dispatching of trains (Caimi et al., 2012), dynamic movements of trains (Kraseman, 2012), changing network capacity (Luéthi et al. 2007; Törnquist and Persson, 2007), route conflicts (Goverde and Meng, 2012) and other dynamic real-time operating characteristics (Corman et al., 2011; D’Ariano et al., 2008; Diaz et al., 1999; Gatto et al., 2009; Wüst et al., 2008) during the course of a disruption.

To date, research has tended to focus on mathematical optimisation and rescheduling of trains and networks, which usually requires high computational processing power which is difficult to deliver in real-time for use by frontline staff faced with hundreds (or thousands) of frustrated customers. Perhaps this is because deciding on a real-time set of objective criteria for rescheduling is just too difficult to define (Yoko and Norio, 2005) and/or too impractical to implement. In contrast, this research has focused on the immediate interface between frontline staff and customers and the generation of requirements for a heuristic (Espinosa-Aranda and Garcia-Ródenas, 2013; Törnquist, 2007) and game-based experiential learning capability (Deterding et al., 2011) for frontline staff with emphasis on learning rather than on optimisation. Other such non-optimisation approaches have been used to investigate other types of delays in rail also not well suited to mathematical optimisation models (e.g. Harris et al., 2013; Tschirner et al., 2014), but these 
previous studies do not lay out any requirements for gamifying frontline staff development and customer service improvement, as in this paper.

In contrast, the aim of this action research project was to increase a TOC's customer satisfaction rates whilst simultaneously reducing its operational costs through better use of information during disruptions by frontline staff. To do this, this paper states what holistic systemic success factors affect the Passenger Information During Disruption (PIDD) management system (as per Golightly and Dadashi, 2017; Tschirner et al., 2014); it also recommends how these may be improved using a gamified learning environment and when they should be used within the Mitigate, Prepare, Respond and Recover (MPRR) emergency / disruption response framework (Drabek, 1996; Fischer, 1998). This research particularly focuses on the latter response and recovery phases of MPRR (Espinosa-Aranda and GarciaRódenas, 2013) and defines conceptual requirements for a gamifying them in a lowrisk learning environment to improve the overall PIDD management system (as per van Lankveld et al., 2017).

This project has been conducted with Chiltern Railways (CR) which operate a mainline passenger service between the West Midlands (Birmingham and its surrounding counties) and London (Marylebone); they run approximately 126,000 services per annum (2\% of all GB services) and have higher-than-average passenger satisfaction rates for the sector (ranked $3^{\text {rd }}$ out of 23 GB's TOCs in 2015). Chiltern is part of the Arriva Group owned by Deutsche Bahn. CR aims to improve their customer ranking by making systemic improvements to their people, process and technological resources. This study took place between November 2013 and April 2015. For reference purposes, a map of the CR network is given in Appendix 1 and, due to the high level of rail-specific terminology used in this paper (Golightly and Dadashi, 2017), a glossary is given in Appendix 2.

\section{APPROACH}

\subsection{Abductive Canonical Action Research (CAR) - an Overview}

The Canonical Action Research (CAR) ontological process (Susman and Evered, 1978) was followed to ensure that an effective action research project was delivered; to facilitate this, a novel type of Soft Systems Methodology (SSM) (Checkland and Scholes, 1996) was used, known as Process-Oriented Holonic (PrOH) Modelling (Clegg, 2007) (see Section 2.2). The ontological process of Canonical Action Research (CAR) (Susman and Evered, 1978) was suitable for this project as it allows real-world situations to be selected, respective roles to be assigned to people in situ (participants) and enquiries about situational conditions (as per Checkland and Scholes, 1996) to be made for retuning elements of the "real world" PIDD management system. Together, this action research team made sense of such situations by referring to the Mitigate, Prepare, React and Recover (MPRR) 
intellectual framework (see Section 2.3). Checkland has stated that "there must be an intellectual framework, declared in advance, in which general learning outcomes can be defined. Without such a framework, action research can quickly become indistinguishable from mere action" (Checkland, 1981, p.400). In this project, $\mathrm{PrOH}$ Modelling served as the specific modelling methodology to enquire into and depict the PIDD management system (see Section 2.2) while the MPRR framework served as the declared intellectual reference framework (see Section 2.3).

\subsection{PrOH Modelling Methodology}

Clegg's PrOH Modelling Methodology (2007) was used to facilitate the canonical action research process. Systemic models, constructed via PrOH Modelling, are considered holons, where a holon is a defensible model of a system under observation - which has subsystems within it and may also be part of a higher-level system (Edwards, 2005; Koestler, 1967). PrOH modelling, like all SSMs, is built upon action research principles; however, unlike other SSMs, PrOH modelling's novelty lies in the fact that it can explore systemic issues by modelling process-oriented holons, and building sets of holons into holarchies as necessary.

$\mathrm{PrOH}$ modelling can also, quite uniquely, be story-boarded to facilitate discussion around complex systemic success factors. As such, PrOH modelling has previously successfully helped organisations form consensus about radical systemic change (Clegg, 2007) and helped overcome aspects of the operations management improvement paradox (Keating et al., 1999). Figure 1 gives the generic template for a PrOH model on which all PrOH models are based. The initial model for this project was also based on this template and re-iterated after each action research cycle in which disruptive incident types were time-lined and work-shopped using a storyboarded version (a scene-by-scene account) of the latest PrOH model iteration. $\mathrm{PrOH}$ models may be thought of as a "mental model" used to explore the PIDD management system as "operators need clear goals, about what to achieve: mental models are their necessary understanding of the involved systems and processes, helping to utilise controllability over a process based on provided observability" (Tschirner, 2014, p.88). 


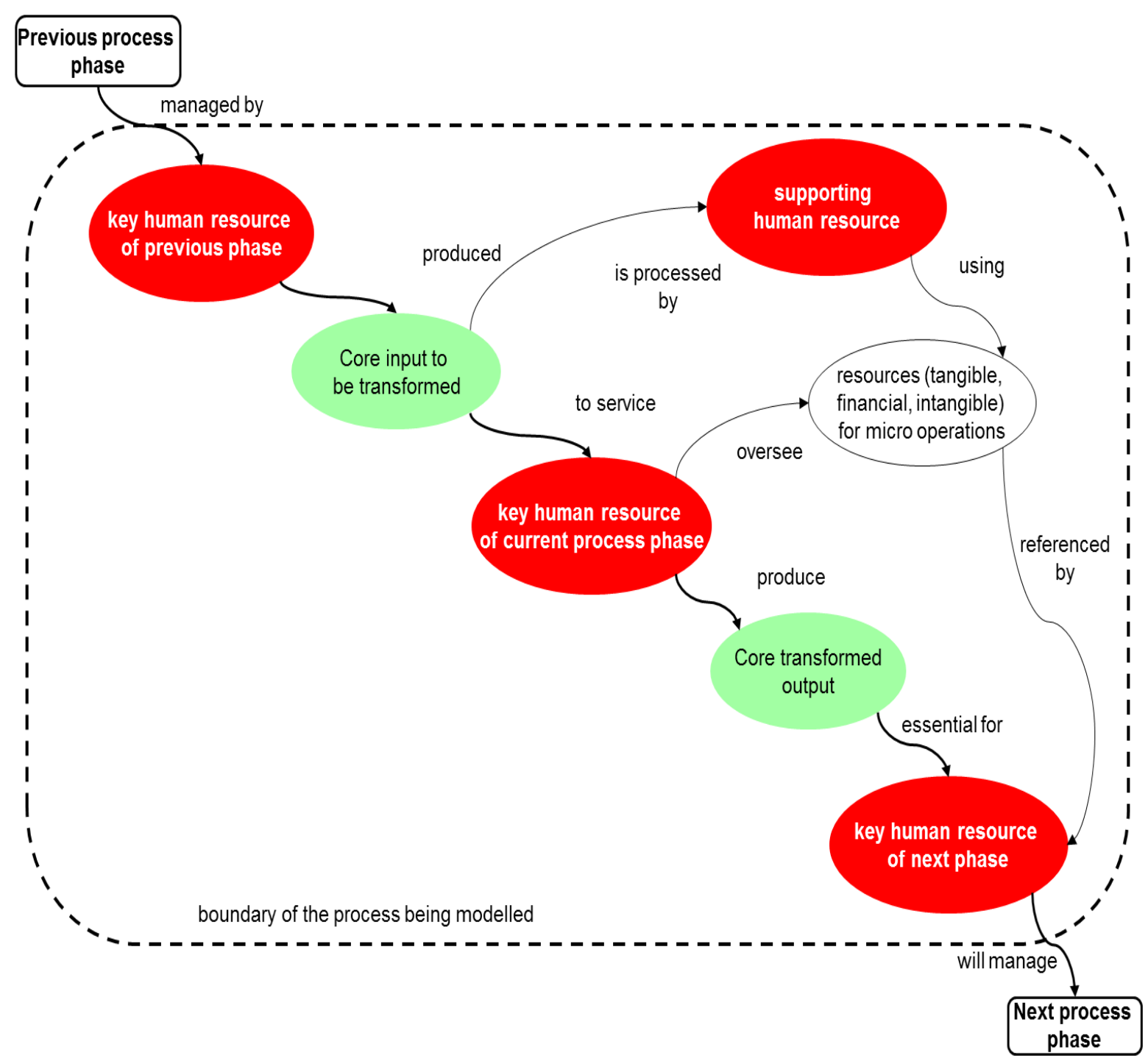

Fig. 1. PrOH Model holonic template - "key human resource of current process phase produce core transformed output”. Source: Clegg \& Shaw (2008)

Figure 1 shows a $\mathrm{PrOH}$ model template; the bold arrows in the $\mathrm{PrOH}$ model template run from top left to bottom right and show the core process description which is necessary to build any holon. The remaining paths in the template show descriptions of supporting activities which are added to and adapted from specific instantiations of the template. Green bubbles contain tangible artefacts, red bubbles contain people or groups of people, and white bubbles intangible factors.

Holons may be strategically, tactically or operationally pitched, and can be connected vertically upwards through abstraction techniques, or vertically downwards through refinement techniques (whether processes are sequentially or parallelically connected); they can also be connected laterally by sequential chaining. The detailed techniques for doing this are not covered in this paper due to reasons of brevity. Instead, this paper focuses on the PIDD management system as the system 
under observation using a single $\mathrm{PrOH}$ model, which was storyboarded and used in incident review workshops to "theory match" the system under observation to suitable reference frameworks (Spens and Kovacs, 2006), critique chronological events, identify systemic success factors and ultimately contribute toward a set of new conceptual requirements for a gamified learning environment (as described in Sections 4,5 and 6$)$.

\subsection{Mitigate, Prepare, Respond and Recover Framework (MPRR).}

Through "theory matching" (Spens and Kovacs, 2006) the MPPR framework came to serve as an a priori intellectual framework upon which to reflect disruptive incident findings and from which to compare and contrast and develop some new conceptual requirements for a new gamified learning environment for the PIDD management system. There are many MPRR type frameworks to choose from (Belmonte et al., 2011; Jennex and Raman, 2009). The MPRR theoretical framework was chosen for this research as it is a simple framework endorsed by the Federal Emergency Management Agency (FEMA) and is used by the USA's Homeland Security to deal with disasters (Drabek, 1996; Fischer, 1996). It needs little explanation other than to say it has four phases: (1) mitigate-referring to activities performed to prevent a disruption from happening; (2) prepare-relating to planning activities needed to perform in case of a disruption; (3) respond-relating to activities to cope with a disruption after it has happened; and (4) recover-relating to activities focused on getting operations back to normal after a disruption has occurred.

The MPRR framework was chosen as it matches the generic process of a rail disruption. Frameworks very similar to the MPRR framework have already been used to explore human factors (Wilson et al., 2006) and human-technologyorganisational perspectives of the PIDD system (Eklund, 2003) in similar ways to this study. Emergency response frameworks, such as the MPRR, help researchers to articulate knowledge and management of knowledge about disruptions (Jennex and Raman, 2009). The MPRR framework can be used on qualitative fuzzy-front-end systemic success factors, as found in the PIDD system, that are usually unforeseen and unpredictable, and have unknown resolutions and uncertain timeframes, properties which make it suitable for use in this study.

The MPRR approach differs from other approaches that focus on quantitative planning models that typically try to optimise train service planning problems (e.g. D'Arano et al., 2008; Leibchen et al., 2010; Vansteenwegen and Van Oudheusen, 2006), train positioning problems and train scheduling problems (e.g. Caimi et al., 2012), which tend to be relatively easier to define and optimise. The contrast between quantitative scheduling optimisation problems and real-time customerfrontline staff interaction-based problems, as focused on in this study, is recognised by Wilson et al. (2003). 


\subsection{Data Collection}

This canonical action research project began by interviewing a cross section of key stakeholders: Managing Director, Passenger Service Director, Commercial Director, Finance Director, Duty Control Managers, Signal Controllers, frontline platform staff, a group of passengers, Train Schedule Planners, Social Media Managers, British Transport Police (BTP), and Network Rail's (NR) Route Control Managers. These stakeholders helped to define the PIDD system under observation and produce an initial generic model of the PIDD system using the PrOH Modelling Methodology.

Stakeholders also selected five contrasting incident types which were subsequently studied as they unfolded in real-time: train breakdown, points' failures, power loss (two examples), fire and fatal accident (two examples). These case types later formed case studies within a case-study as per Voss' case study principles (Voss 2009). Types were selected to provide contrast and breadth to the study (as per Eisenhardt, 1989 and Yin, 1994). Seven cases were considered a parsimonious and "theoretically useful" (Voss, 2009, p.180) number for this study considering its boundaries and timeframes (Miles and Huberman, 1994) as they might "potentially produce contrary results for predictable reasons (e.g. a theoretical replication)" (Voss, 2009, p.172). These incident types are detailed in Section 4.

Disruption types were each investigated using information gathered from interviews with key people involved in each incident, observations in real-time and use of incident-specific documentation (e.g. Network Rail-specific communication made via the Network Rail Tyrell information system, CR control logs, Area Director's logs, Network Rail Route Control messages, and passenger satisfaction surveys) (similar to Glover, 2013). From each type of incident, the research team produced a detailed chronological timeline of events.

The systemic properties of each incident type were then debated in a stakeholder workshop using a storyboarded version of the initial generic $\mathrm{PrOH}$ model together with the actual timelines (given in Section 3). During these workshops,

- chronological timeline events were questioned;

- systemic failings were highlighted by the PrOH model; and

- academic frameworks which may potentially help to improve the PIDD system, and develop user requirements for a gamified learning environment, were posited and reflected upon.

Reflecting on a priori frameworks in this manner is a key activity in abductive action research, as abductive reasoning is a process of logical inference starting with an observation and seeking to find a likely explanation-whereas, in scholarly action research, an academic framework is normally used to give the explanation. In this study, the most suitable abductive framework posited after investigating three incidents was the Mitigate, Prepare, Respond and Recover (MPRR) framework 
(Drabek, 1996; Fischer, 1998) (Section 2.3). Once validated as a fit-to-use framework, after two further incident investigations were applied to it, and through consultation with the train operating company experts, the MPRR framework was forthwith used as an academic reference framework for describing "when" gamification measures could be used, and for comparative benchmarks of CR's practice to BTP's and London Underground Ltd.'s (LUL) methods of dealing with disruptions, both of which are key organisations in this PIDD management system.

This type of action research is referred to as abductive (Spens and Kovacs, 2006) because it supports reasoning from effect to causes or explanations (Lamma et al., 1999). This study considers the PIDD management system as its system under observation or its puzzling observation or an anomaly that cannot be explained using established theory (Andreewsky and Bourcier, 2000) and uses the MPRR theoretical framework to provide a deliberate application of an alternative theory for explaining a phenomenon (Kirkeby, 1990) achieved via theory matching (Dubois and Gadde, 2002). The use of abductive logic, by pattern matching to such an a priori framework, helps to induct new knowledge about the initial system under observation (e.g. the PIDD management system).

Seven cycles of Canonical Action Research (CAR) took place as each incident was investigated as described below in Section 3. In effect, for this study, the CAR process is a two-stage investigation which (i) starts with an initial $\mathrm{PrOH}$ model produced from expert knowledge which was then (ii) iterated after each empirical case. Both steps are interdependent and iterative; however, the authors firstly present the overall PIDD system (Section 3) and then present the individual cases (Section 4) to define "what" should be gamified in the PIDD system. Toward the latter cycles of CAR the "how" (Section 5) and "when" (Section 6) conceptual requirement dimensions begin to emerge.

\section{THE PIDD SYSTEM}

A strategic view of the PIDD management system, shown as a holonic PrOH model, is given in Figure 2. Figure 2 shows strategic systemic interactions in the PIDD system; the PrOH model is used in a similar way to Tschirner's mental model as both provide "The holistic view ... to identify problems in the interplay of humans and technology in the complex organisational structure of railway traffic" (Tschirner, 2014, Fig. 1, p.89). The PrOH model given in Figure 2 is the final version after seven iterations based investigation of each disruption. The main input to this $\mathrm{PrOH}$ model holon is "Disruptions" (top left-hand corner: green bubble). 


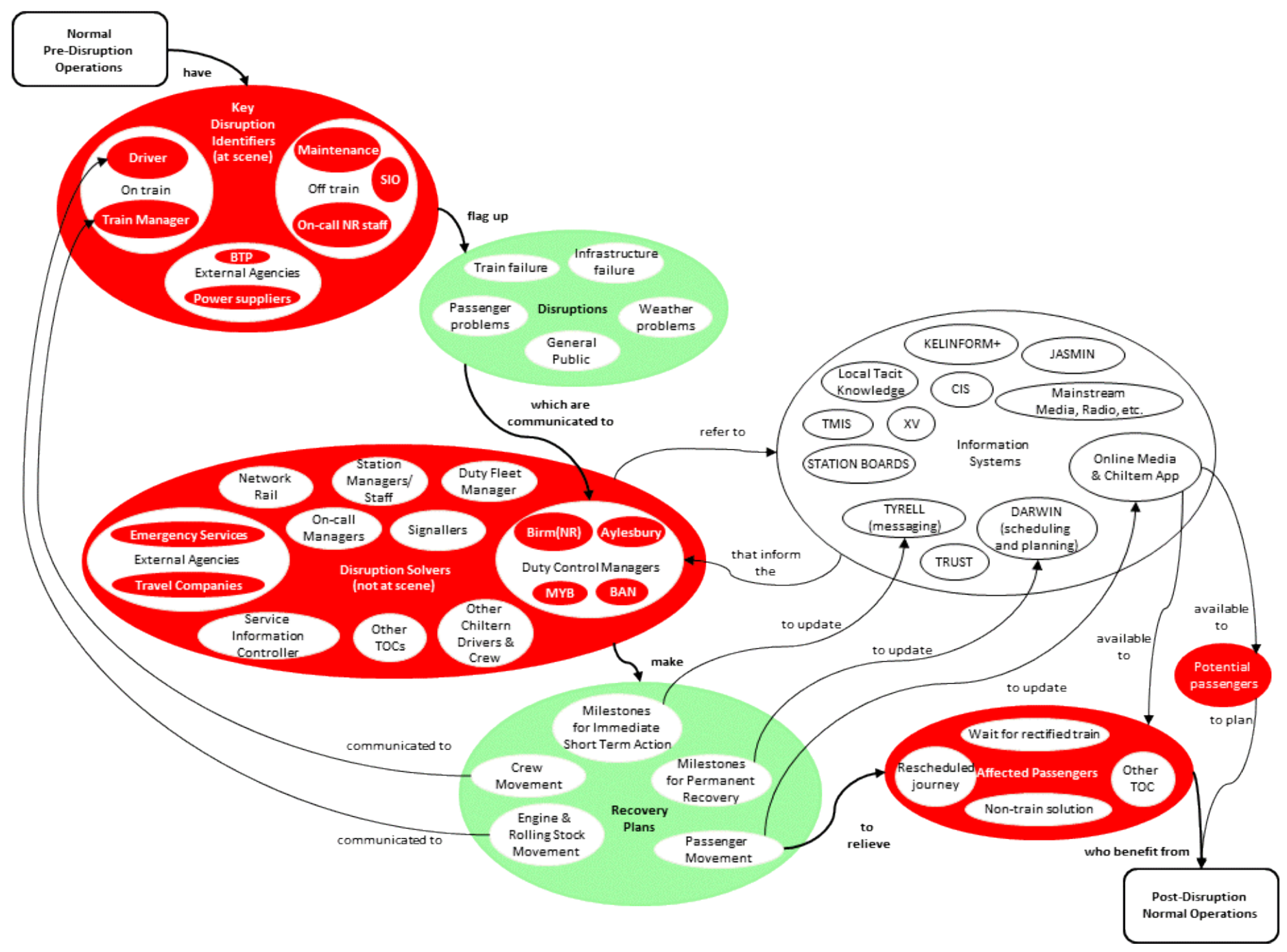

Fig. 2. PrOH Model of the PIDD management System - 'Duty Control Manager makes recovery Plans for PIDD'

The most significant role in this PIDD management system (see Figure 2) is that of "Disruption Solvers (not at scene)" which is placed in the red bubble in the centre of the model, which, surprisingly, was not a role formally identified in "normal" customer service (Customer Service Level 1 or CSL1) operating conditions. Primarily this role includes leadership from "Duty Control Managers (DCMs)" at stations, with significant support from "Duty Fleet Managers", "Station Managers", "Signallers", "Network Rail Managers", "Drivers" and "Crew", "On-Call Managers" and "Other TOCs" who reciprocate supportive actions during disruptions.

Another key role in this PIDD management system is the "Key Disruption Identifiers (at the scene)", which surprisingly was also not a role recognised during normal operations, whether they be on the train (e.g. "Driver" or "Train Manager") or off the train (e.g. "Maintenance" or "On-Call NR staff"). Often, problems are rooted in the fact that these temporarily recognised roles of "Disruption Solvers" and "Disruption Identifiers" are geographically separated, void of effective two-way communication, 
and reliant on information systems that are too slow to report on rapidly changing events that occur during a rail service disruption. The hiatus between "those at the scene" and those "not at the scene" is also recognised by Panou et al. (2014), Tschirner (2014), Golightly and Dadashi (2017) and Farrington-Darby et al. (2006) but not yet fully recognised or remedied by TOCs in practice.

Another critical group in this PIDD management system includes the "Affected Passengers" who wait to have their train service rectified, rescheduled or transferred to "Other TOCs" in the event of a Customer Service Level 2 (CSL2) status being declared (CSL 2 is when CR tickets are useable on all other TOCs, or other forms of public transport, operating over the same network), or are provided with a "Non-train solution" (e.g. "Bus or Taxi").

Other significantly affected roles in this system are "Potential Passengers" who must be forewarned of any disruption so they can take proactive measures to minimise their own inconvenience and help prevent further exacerbation of the problem by entering into an already overloaded system.

In periods of normal CSL1 operations, these roles have "Information Systems" and procedures fit for purpose. For instance the "DARWIN" information system is a "Network Rail" (NR) system used for planning and scheduling which connects all TOCs to NR, with a medium-to-long-term planning horizon (from hours to days). Tyrell, at the time of writing, is a one-way TOC industrywide system enabling "DCMs" to broadcast to other roles in the company. The choke point in the system comes as only DCMs (through a "Station Information Controller" [SIC]) can broadcast to all parties using the Tyrell system, and other roles have to communicate with the DCM using other alternative channels of communication to update the DCM of any changes to an unfolding situation. Messages of all types (e.g. phone, emails etc.) can easily run into hundreds per hour. Significantly, to be able to achieve a resolution to disruption that is both appropriate and timely, the DCM requires an accurate estimation of time to remove/fix the cause of the disruption; without this any planned response may be merely a 'best guess' based on past experience. Thus speedy and accurate communication of information is vital for effective response and recovery to provide an acceptable customer service level. This is because, as a disruption unfolds, the complexity of the system and deviations from a planned schedule can increase dramatically (Golightly and Dadashi, 2017). Communication channels also quickly become overloaded, and, to make matters worse, the DCM (through the SIC) cannot update the Tyrell system whilst taking incoming updates from these other channels; this phenomenon has also been observed by Kauppi et al. (2006).

An "app" for mobile devices is provided free of charge by Chiltern Railways to update passengers in real-time for train positioning (based on the track section in which the train is currently located); however, additional information messages about delays 
and what to do are manually input based upon other Tyrell-formatted messages whose uniformity varies greatly. Often, it is the case that passengers and TOC operatives alike become informed about new disruption developments by other passengers using their publicly available social media (e.g. Twitter) before any official operational explanation reaches frontline staff, and, given that these unofficial messages cannot be taken as accurate, they add to the uncertainty and speculation between frontline staff and passengers on incidents, which can be a source of great frustration for all parties involved. As stated by Glover (2013, p.83), "It is most disconcerting for station staff in times of service disruption, when they are trying to do their best for passengers, to have someone come up and tell them more about the service than they themselves know".

"TMIS" is another real-time information system providing information on train position (by track sector) which can be assessed by those in offices (e.g. major signal boxes and control centres) but not by those on a train or at the scene of an accident. There are also many other passenger/customer information systems (e.g. "JASMIN" and "KELNFORM+") which play a significant role in PIDD management system, but fall out of the scope of this particular study.

Local tacit knowledge of TOC's frontline staff on other transport systems located near a railway station also plays an important part in the PIDD system (Figure 2) which, depending on its accuracy, either helps or hinders the PIDD system. The effectiveness of this knowledge is largely dependent on the competence, confidence and experience of TOC frontline staff, thus making the need for gamified learning initiatives for PIDD management timely, relevant and important (Abdelatif et al., 2015).

Presently, those most in need of up-to-date information, in other words those "Disruption Solvers" (not at the incident scene), don't get it, as "Train Drivers" cannot use a phone whilst driving, "Train Crew" don't have access to Tyrell, Internet-based systems have only weak coverage in rural areas and electrified rail track areas, and there is no coverage in tunnels where incidents commonly occur. Thus, TOC frontline staff "not at the scene" are reliant on calls made on two-way radio messages by "Drivers" that are only possible when trains are stationary, which is seldom the case. Alternatively, calls can be made by the "Online Train Crew" whilst the train is moving, as they are able to receive a communication signal from the signallers in signal box who are informed directly about a situation, which is more common. Neither scenario is ideal as information of this form will be partial and not fully contextualised (Panou, et al., 2014). Likewise, signal boxes will only have up-todate information about an incident if the incident is very local or the Network Rail Mobile Operations Manager (MOM), or a TOC DCM in the control centre has been able to update the "Signallers". Non-Tyrell messages in the PIDD management system are also asynchronous with Tyrell and may not be exactly the same or received at the same time as Tyrell messages. Hence, official messages may be different than the social media messages received by passengers. Herein lies the 
root of confusions and delays in the PIDD management system, which contribute to high customer dissatisfaction. These systemic success factors are all depicted by the interlinking sentence descriptions in the $\mathrm{PrOH}$ model given in Fig. 2, as just described.

Therefore, in times of disruption, the PIDD management system has systemic failures, due to a combination of ill-defined roles, inappropriate operating procedures, misused information system functions, information-overload, asynchronous processes and unchecked human behaviour. Indeed, some studies in other companies have even reported that some operational systems are so problematic during disruption that they get turned off to prevent confusion (Balfe et al., 2012). So the same resources which are sufficient in times of normal operations (i.e. CSL1) cannot respond adequately, in the opinion of passengers, in times of disruption. The holonic model of the systemic success factors in the PIDD management system (Fig. 2) is therefore akin to an evaporable cloud of systemic problems created by a disruption which then vanishes during the last two phases of MPRR. Researchers have not previously attempted to fully capture and study these nefarious systemic success factors because recording them is usually too difficult and the last thing on the minds of a PIDD team during an actual incident (i.e. CSL2 conditions).

Capturing such systemic PIDD behaviour is challenging but it has been achieved in part by this study through prescient generic soft systems modelling activities followed by real-time observation of seven disruptions (data for the PrOH model of the PIDD management system in Fig. 2). Fig. 2 also reveals some of the systemic success factors for making "Recovery Plans"- the main outcome of the PIDD management system.

\section{INCIDENCES OF DISRUPTION - "WHAT" TO GAMIFY}

Five incident types illustrate the main types of CSL2 disruptions which occur (adapted from Glover, 2013) (see green 'artefact' input bubble in the left hand corner of the PrOH model in Fig. 2). For brevity, only the most relevant idiosyncrasies of each type of disruption are time-lined and discussed in this paper. Similar issues and scenarios have been reported by Kauppi et al. (2006) in Sweden. Whilst timelines given in this study are simplifications of reality, care has been taken to retain salient properties to demonstrate authenticity and fidelity (as endorsed by van Lankveld et al., 2017); Appendixes 1 and 2 should be referred to for locations and UK-specific rail term explanations.

\subsection{Train breakdown}


This incident type is illustrated using the events during a freight train failure at Gerrards Cross on the afternoon of February $12^{\text {th }} 2014$ and the impact upon CR's services. The train initially came to a standstill on the main line at 15:00hrs and was declared a failure by the driver at 15:15. At 15:52, locomotive 66160, hauling a goods train, was identified as a suitable rescue locomotive and was held at High Wycombe station. However, due to the sensitive (military) nature of the cargo pulled by locomotive 66160 , one platform at High Wycombe had to be closed to the public and it was necessary to source a member of British Transport Police (BTP) to secure the wagons left on the running line. Further confusion arose over where was the best place to remove the failed train. Eventually, a decision was made to recover it to Aylesbury, which in turn trapped two diverted Birmingham trains and further affected both the passengers on board and CR's overall service recovery. The incident was closed at 22:54, by which time a significant number of trains had been fully or partially cancelled and those which had run had been subject to severe overcrowding. Further details of this incident are given in the timeline in Fig. 3.

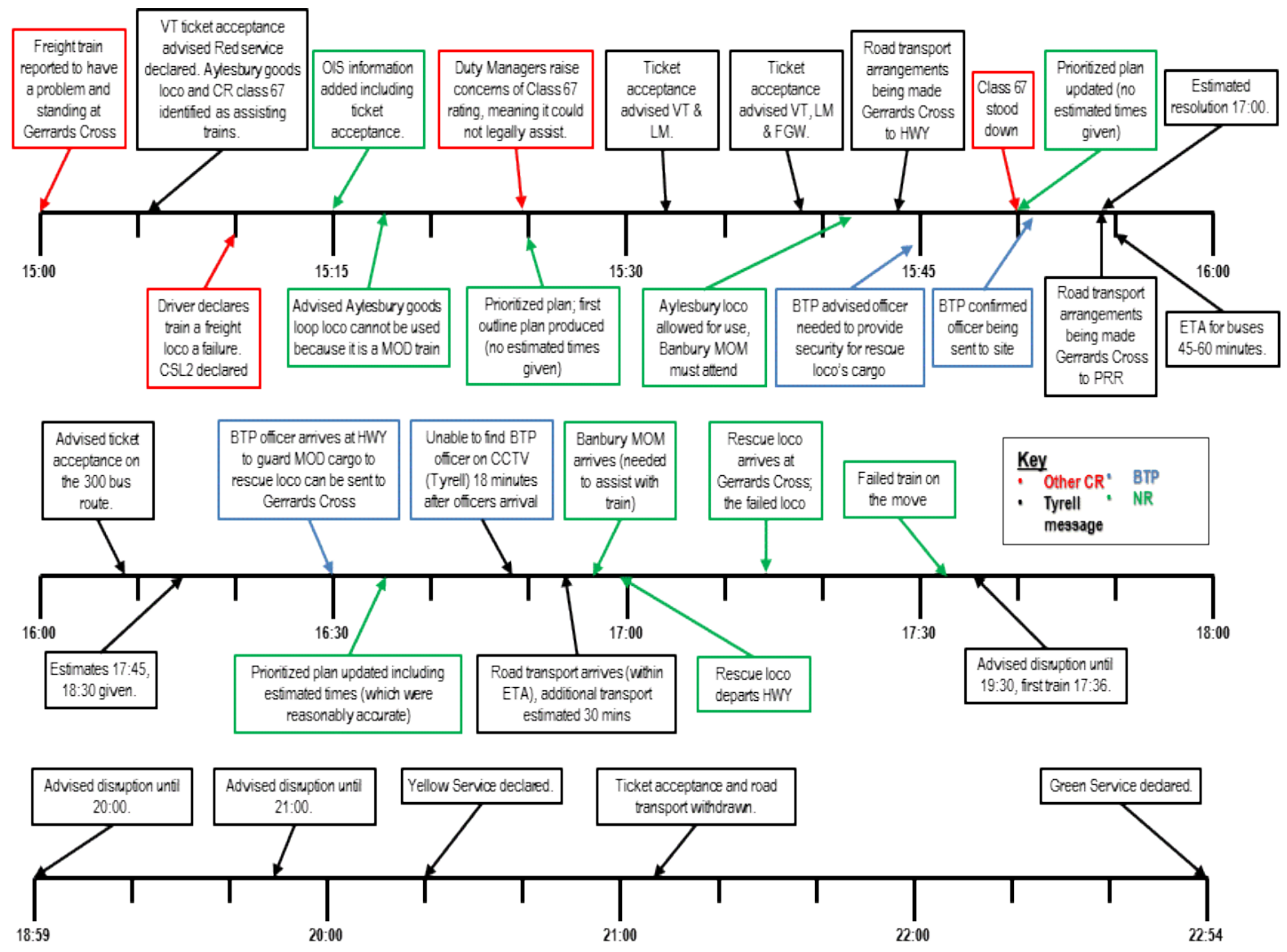

Fig. 3. Timeline for failed freight train.

The overall reflective consensus of the PIDD team was that the management of this incident was "good" with some areas for improvement. The problems were caused 
by constant slippage of estimated recovery times due to initial misdiagnosis of the disruption and subsequent iterations and re-iterations of recovery plans. The overall timescale between the incident being declared to NR and the broken-down freight train being moved was eventually 2 hours and 33 minutes. This relatively lengthy time, bordering on a major incident, was due to having to obtain a suitably rated recovery engine from the Ministry of Defence (MoD), an external agency. Had an alternative recovery engine with an adequate hauling rating been available, then the recovery time and the return to normal operation could have been faster. Customer advice and communications and the formalisation of a prioritised plan were initially hindered by high uncertainty. The uncertainty caused high-loading of phone calls to Chiltern Railways Control (CRCL) which caused further delays to a mid-term solution. On the positive side, CSL2 was declared swiftly, and alternative routes and road transportation were available for this location.

\subsection{Points failure}

This incident type is illustrated by a point's failure at Marylebone (MYB) on the morning of $6^{\text {th }}$ February 2014. The early morning timing of the incident meant that some key TOC PIDD team members were themselves caught in the disruption as they made their way to work. This contributed to a shortage of experienced staff, both in terms of their presence on the station and their ability to contribute to decisive and effective decision-making as communicating with them was difficult. The rail points in question (no.ME813) were critical to providing a basic service, and the ensuing reduced service meant that passengers were left behind on the platform. The failure was exacerbated by industrial action by members of the Rail, Maritime and Transport (RMT) Union which diminished the services of London Underground Ltd. (LUL) as the normal response was to shift passengers to LUL. Delays in understanding the root cause of the problem led to inaccurate forecasts for clearing the disruption, which in turn created anxiety and frustration in passengers. Further details of this incident's timeline are given in Fig. 4. 


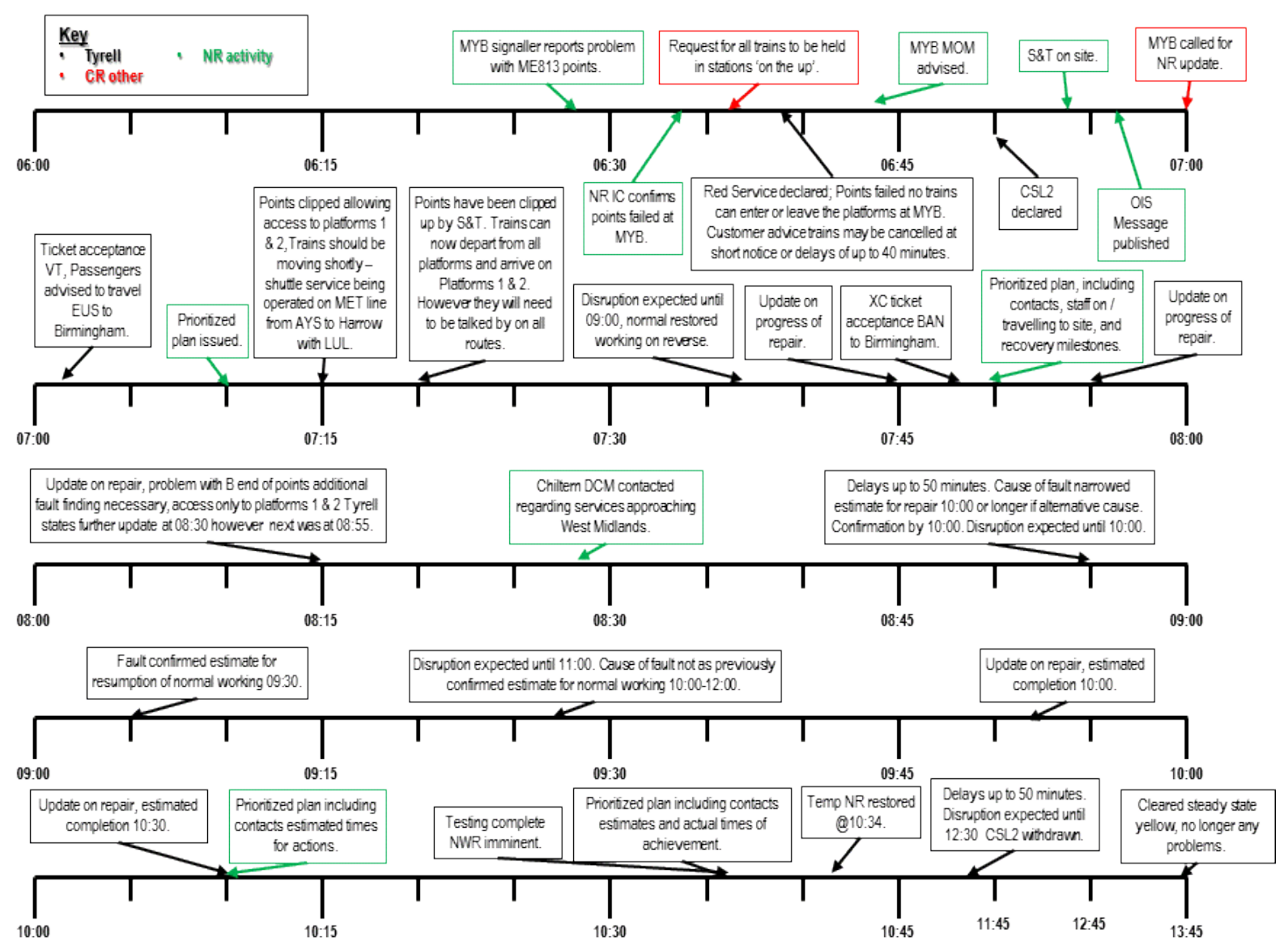

Fig. 4. Timeline for points failure.

The reflective consensus of those involved was that the overall management of the incident was that it was "adequately handled" but had possible areas for improvement which could have reduced the extended fault-finding period (NR responsibility) and increased the amount of recovery options available. The overall timescale between the incident occurring and normal working practice being restored was 4 hours and 10 minutes -in other words, a "major delay". Access to Platforms 1 and 2 and limited train movements were restored after 42 minutes. The delay for completely resolving the incident was due to the intermittent nature of the failure which made the identification of the root-cause more difficult. Noted areas for improvement in this incident related to having higher staff skill levels and clearer operating procedures to increase the clarity of information shared. For instance, the efficiency and speed of communication could have been improved and more consistent messages could have been communicated across information systems, especially those messages given through Tyrell. More could also have been done to inform the public of other available sources of service information. 


\subsection{Fatalities}

This incident type is illustrated by two occurrences: one at Mantleswood on Tuesday February $4^{\text {th }} 2014$ and one at Willesden Green during the evening of Wednesday $12^{\text {th }}$ November 2013. Both incidents occurred during the evening peak, meaning that stations and train services were at their busiest. In both incidents, once British Transport Police (BTP) had established there were no suspicious circumstances (e.g. murder or gross negligence) and no ensuing criminal investigations (which BTP aim to do in a one-hour service-level target) were required, the recovery plans and duration were able to be declared with greater certainty. See Fig. 5 and 6 for further details on these incidents' timelines.

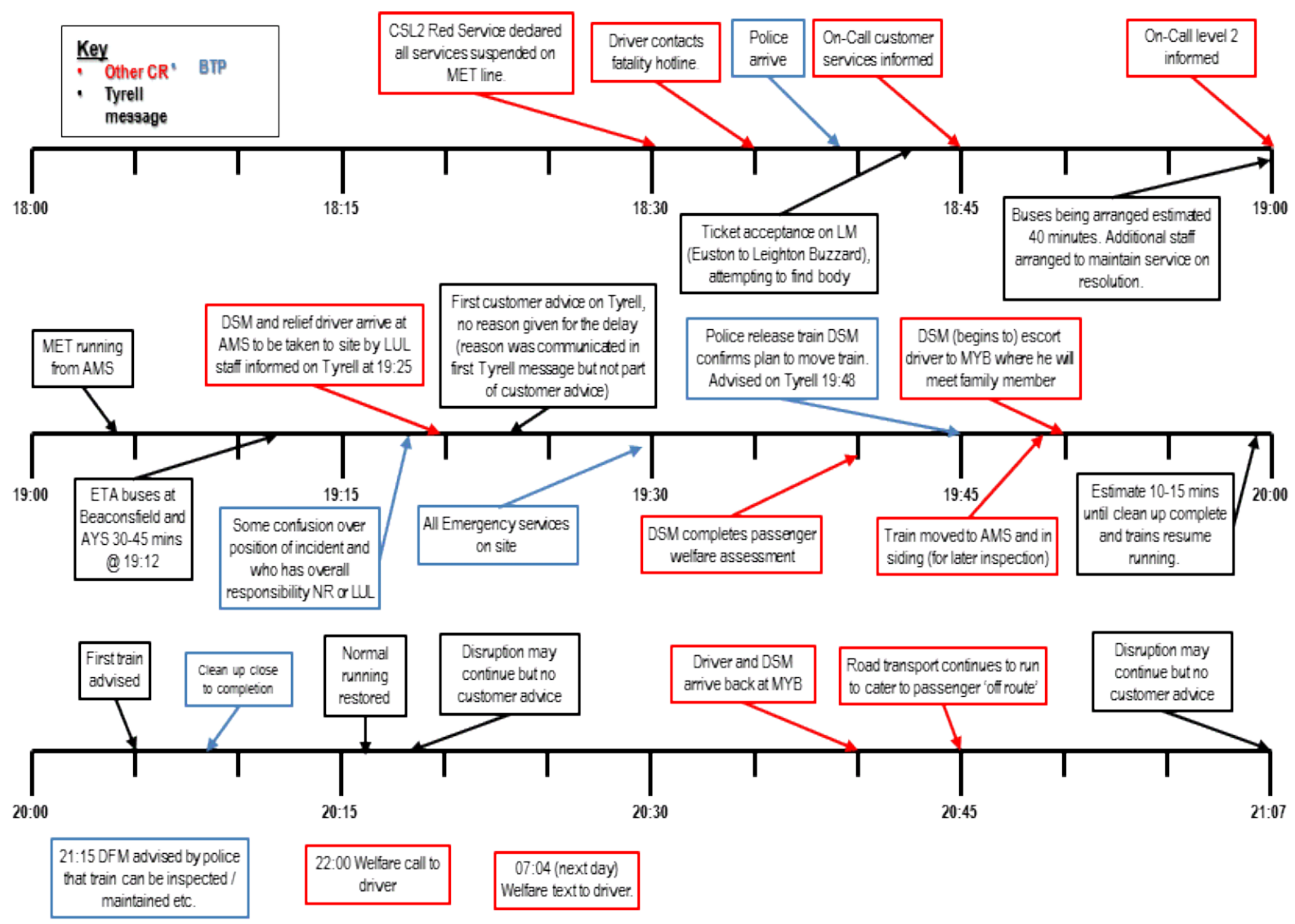

Fig. 5. Timeline for fatality (Mantleswood). 


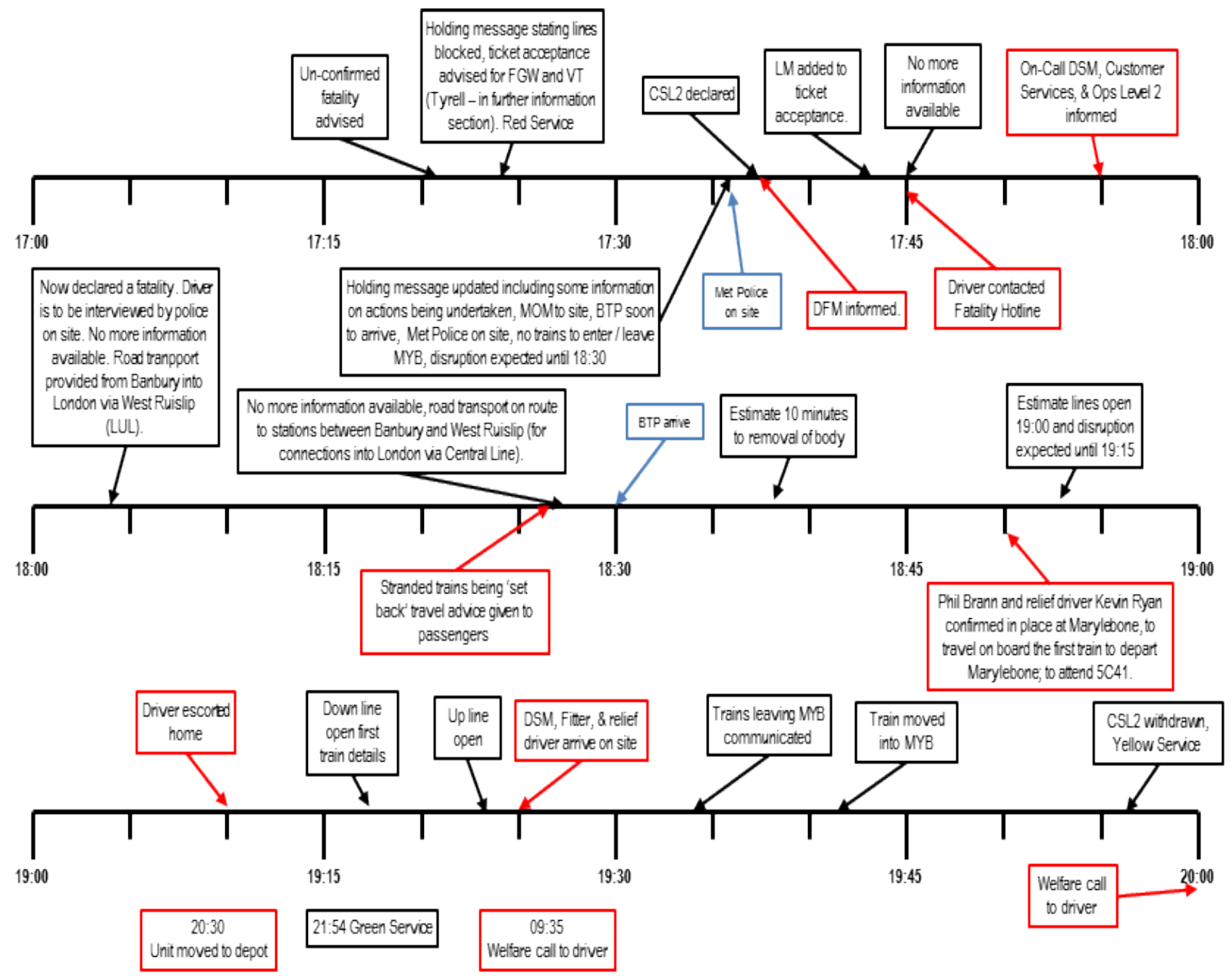

Fig. 6. Timeline for fatality (Willesden Green)

Ironically, despite the fatal nature of these incidents, the recovery timelines were quite predicable, which helped staff to quickly provide information that had a high degree of certainty to passengers. Declaration of CSL2 was swiftly declared, which helped prevent the PIDD management system from becoming too overloaded. Quick recovery was also helped by rapid response from the BTP in both cases. However, in the case of the Willesden Green incident, resuming normal service was hindered slightly because the track where the incident happened was under the jurisdiction of LUL_and not NR; therefore, updates about infrastructure changes were slower than normal to trickle through the PIDD management system.

\subsection{Loss of power}

This incident type is illustrated by a loss of power in the Banbury area during the evening of Wednesday $12^{\text {th }}$ February 2014, and by a loss of power in the Princes Risborough area during the afternoon and evening of Sunday $17^{\text {th }}$ August 2014. 
In the first instance, a fault with the high-voltage overhead cables (responsibility of Western Power Distribution) led to a power cut, affecting over 2,000 properties in the Banbury area, including Banbury station itself. It also resulted in the loss of all signalling around the Banbury and Aynho junctions. The incident occurred during a period of severe weather which had already contributed to disruptions across the rail network and had already put additional pressure on road transport. Power was restored to the majority of the affected properties after around 75 minutes, but further problems with the signalling equipment meant that disruption to train services continued for several hours afterwards. The incident was characterised by poor provision of information to customers as only generic advice was offered, and, in some cases, there were gaps greater than one hour between passenger information updates. To make matters worse, the power loss also affected some electronic rail information systems which were normally used to inform passengers about rail disruptions.

In the second incident, an external UK power network cable fault caused loss of power to the signalling between Bicester and Princes Risborough shortly before 14:00 hours. It was recognised relatively quickly that this problem was not likely to be resolved easily, and this fact was conveyed to passengers. However, the situation was further complicated by the planned closure of the West Coast Main Line for engineering works. This meant that passengers travelling between London and the West Midlands, who were already subject to travel disruption, were now affected by two different separate major incidents. Managing passengers at Princes Risborough became a major problem, with the sheer volume of passengers making it difficult to load and embark replacement bus services, and it was too difficult for frontline CR staff to make themselves heard when travel advice was issued to passengers. The last hour of this incident was characterised by particularly poor communication between stakeholders which resulted in passengers being given little information, some of which was also misleading, about when services might resume. The detailed timelines for these incidents are given in Fig. 7 and 8. 


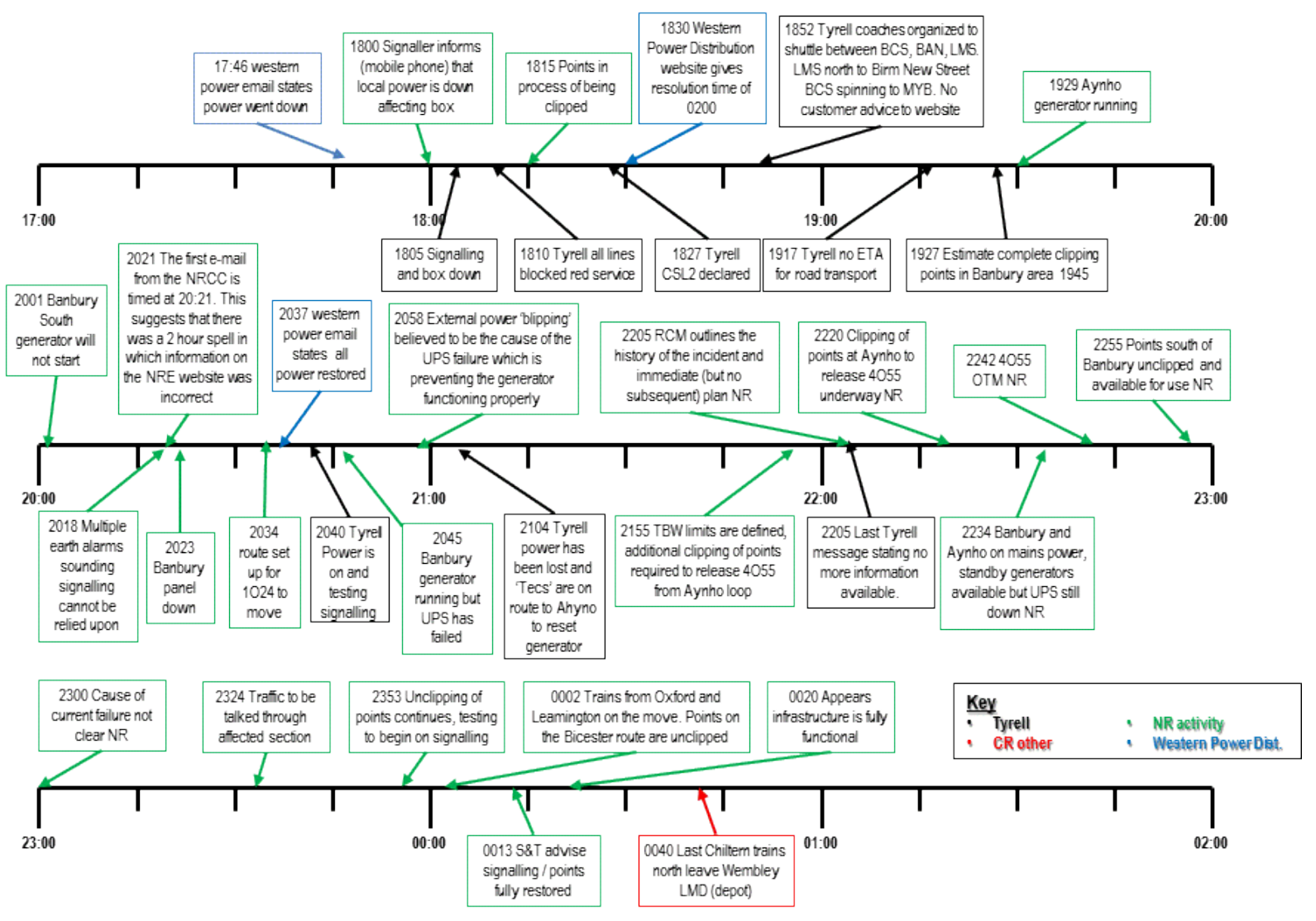

Fig. 7. Power failure (Banbury)

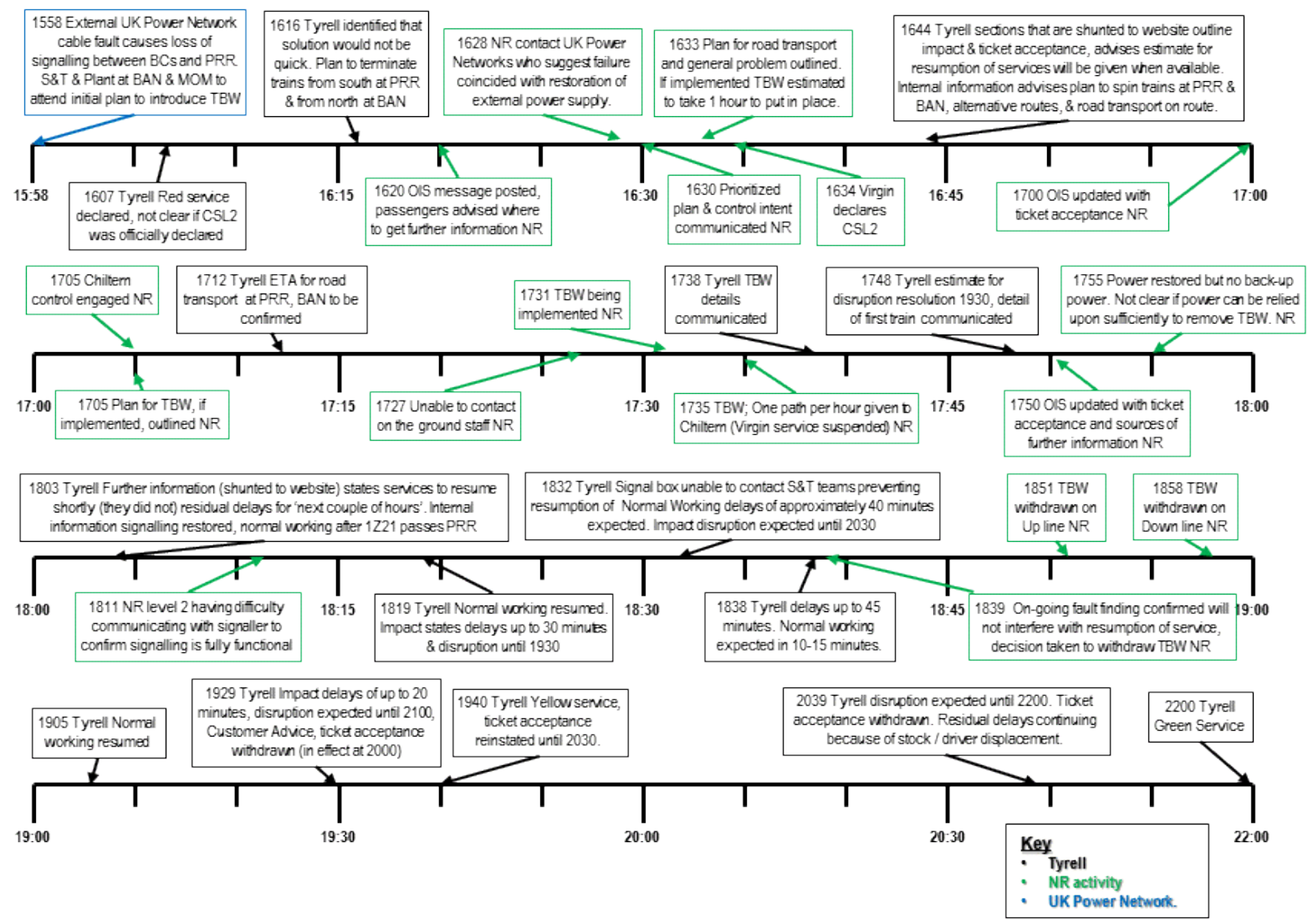

Fig. 8. Power failure (Princes Risborough) 
The general perception was that the incident affecting Banbury was poorly managed with very little useful information being communicated; moreover, failure of the backup infrastructure and poor communication between geographically remote sites further exacerbated the incident. The management of the Princes Risborough incident was considered as "relatively good" except that normal CSL1 working was expected to be resumed at approximately 18:15 hours; however, poor communication resulted in confusion (e.g. incorrect passenger information) and a delayed reinstatement of CSL1. Unfortunately, customer service feedback rated this incident as "poor".

\subsection{Cable fire in tunnel}

This incident describes the protracted events involved following a cable fire in the tunnel at St. John's Wood. The incident was discovered in the early hours of Sunday morning June $15^{\text {th }} 2014$ and resulted in the closure of Marylebone station until the morning of Tuesday $17^{\text {th }}$ June 2014. The timeline of this incident is extensive as the incident stretched over three days; see Fig. 9a, 9b and 9c. Initially, this incident was reported as a "minor incident" as it was believed that just a single two-metre stretch of cable had burnt out. However, in fact, once the fire had been extinguished and the damage had been fully assessed, it turned out that 30 cables needed to be replaced in and around a cabling junction box which meant total closure of the tunnel was necessary whilst complex repairs were carried out by NR. During the early stages of this incident, engineering works were constantly affecting the react and recovery timeline which was extended from "minor" to "major" as critical damage was revealed piece-by-piece over time. BTP and the Fire Service also had to investigate the scene to ensure that arson hadn't been committed, which was a possible further complication. 


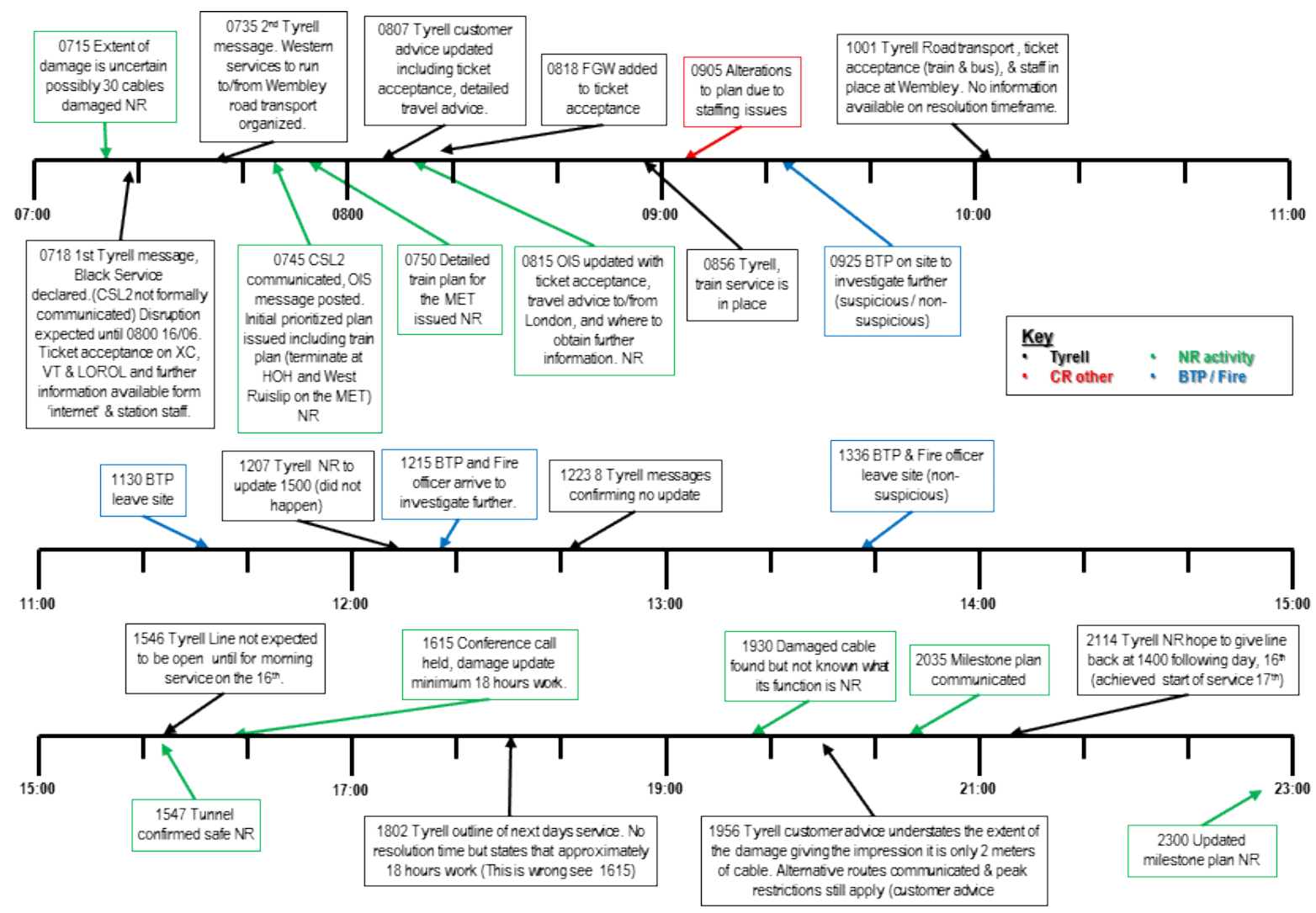

Fig. 9(a). Fire in St. John's Wood Tunnel.

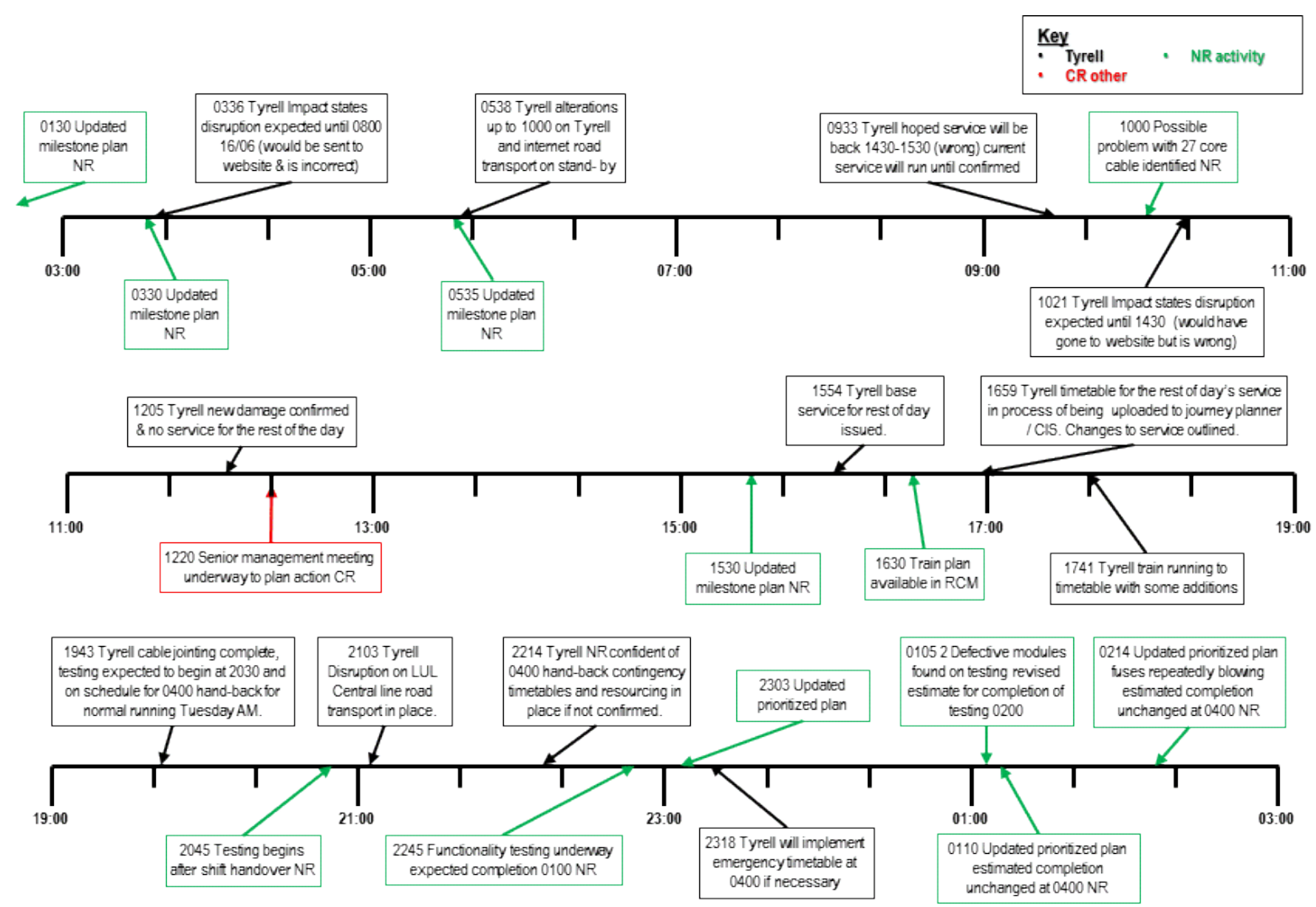

Fig. 9(b). Fire in St. John's Wood Tunnel. 


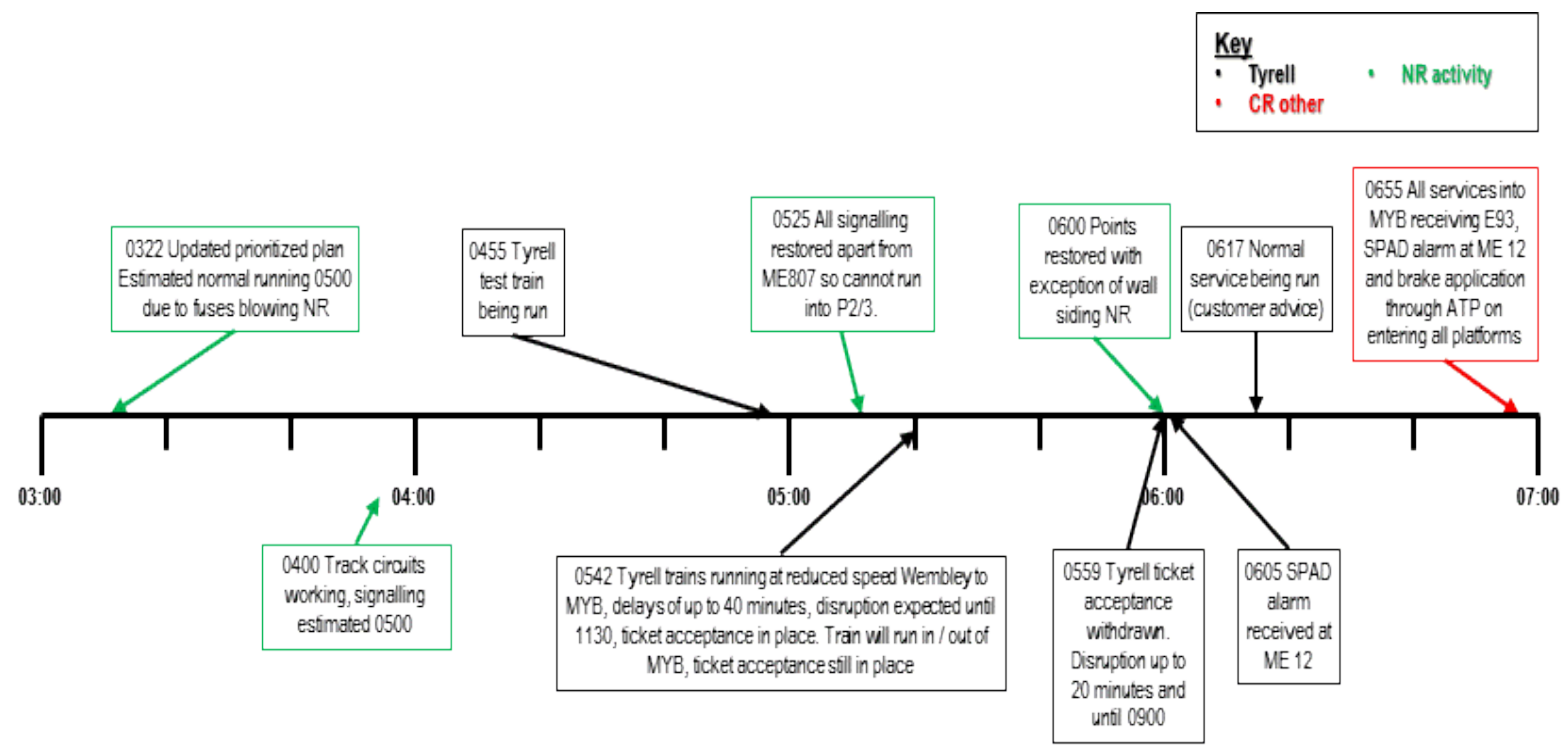

NOTE: The E93 and SPAD alarms activated at ME12 and the brake application through ATP entering all platforms was managed as a separate incident and resolved in a similar manner to a normal points failure. The problem was relatively easy to manage and while possibly a result of the cable fire is not included as a part of the case study.

Fig. 9(c). Fire in St. John's Wood Tunnel.

On reflection, the general perception was that the incident could have been managed more effectively in the initial stages while the extent of the problem was not fully understood. Later on during the incident, the management of the incident became far more effectively managed once a more accurate estimate for repairs was apparent. In this case, the provision of customer information was considered to be handled "reasonably well" by passengers. Moreover, it was just fortunate that the incident had occurred on a Sunday morning when there was relatively little passenger traffic, and demand and capacity planning for the following Monday morning's commuter service could be re-planned fairly effectively in time. Also, once it was certain that the Marylebone station would have to be shut for a substantial period of time, rail services running from some Marylebone platforms were significantly and quickly rescheduled to run from other platforms, across other infrastructure (e.g. London Underground and London Overground), or from other nearby stations just beyond the outward-bound end of the tunnel from the Marylebone Station terminus.

It is therefore desirable to be able quickly to understand the severity and uncertainty levels of such incidents. Being able to do so meant that no short-term solution to the tunnel fire would be possible, and a "major" cancelling and rescheduling of services from the mid-to-long term had to be implemented immediately. In hindsight, passengers felt that "adequate" advice had been given to this effect and service levels had been acceptable considering what had happened. 
Of all the incidents studied in this project, this tunnel fire case was by far the most extensive, complex and time consuming to resolve. It was however coped with remarkably competently by the TOC staff because "normal" PIDD recovery procedures, which are too slow to react to even "minor" disruptions (e.g. by using Tyrell and TMIS in CR, and DARWIN in NR linking to other TOCS), couldn't be used at all in this "major" disruption.

Across each incident, the generic systemic success factors were coded (King, 2004) into a repertory template given in Table 1 (in a similar way to Golightly and Dadashi's [2017] classification of incident types). These systemic success factors were common to all cases and show "what" should be addressed by a gamified capability of improving the PIDD management system. Red cells show areas for improvement, green cells show examples of good practice and white cells show satisfactory performance. Overall, the high proportion of red cells suggests that there is a strong need for developing a new learning capability to help improve the quality of customer service provision during rail disruptions. 


\section{Table 1}

Repertory template showing 'what' systemic success factors to address across investigated case Incidents

\begin{tabular}{|c|c|c|c|c|c|c|c|}
\hline & \multicolumn{7}{|c|}{ Incident Type } \\
\hline $\begin{array}{l}\text { Systemic success factors - from analyses of specific } \\
\text { disruptive incidents }\end{array}$ & $\begin{array}{c}\text { Train } \\
\text { Breakdown }\end{array}$ & $\begin{array}{l}\text { Points } \\
\text { Failure }\end{array}$ & $\begin{array}{l}\text { Fatality } \\
\text { (M'wood) }\end{array}$ & $\begin{array}{l}\text { Fatality } \\
\text { (W'Grn) }\end{array}$ & Fire & $\begin{array}{c}\text { Power } \\
\text { Loss (Ban) }\end{array}$ & $\begin{array}{l}\text { Power Loss } \\
\text { (PRR) }\end{array}$ \\
\hline Improve resolution estimates (slippage) & & & & $x 2$ & $x 3$ & $x 2$ & $\times 3$ \\
\hline $\begin{array}{l}\text { Better definition of disruption (normal working (CSL1) vs end of } \\
\text { disruption to customers) }\end{array}$ & $x 2$ & & & & $x 2$ & & \\
\hline Better management of external agencies & $x 3$ & & $\begin{array}{l}x 2 \text { (plus } 1 \\
\text { good) }\end{array}$ & & $x 2$ & x3 & \\
\hline Clearer notification of alternative routes for passengers & $\mathrm{x} 2$ & & $x 3$ & $\begin{array}{l}\text { x2 (plus } \\
x 1 \text { good) }\end{array}$ & $x 2$ & $x 2$ & $x 4$ \\
\hline More consistent message formatting in Tyrell & & $x 2$ & & & $x 3$ & $x 2$ & \\
\hline Better customer advice & $x 2$ & $x 3$ & $x 2$ & & $\begin{array}{l}x 2 \text { (plus } \\
x 1 \text { weak) }\end{array}$ & $x 2$ & x3 \\
\hline Communication of prioritised plans \& control intent & $x 2$ & & & & & & $x 2(+x 2$ good $)$ \\
\hline Quicker provision of more suitable road transport alternatives & $x 2$ & & $x 2$ & $\begin{array}{l}\text { x2 (plus } \\
\text { x1 weak) }\end{array}$ & & $x 2$ & \\
\hline Consistent messages throughout PIDD management system & & $\mathrm{x} 4$ & & & & $x 2$ & $x 3$ \\
\hline Clear and timely identification of the problem / disruption & & & & & $x 2$ & $x 2$ & \\
\hline Improve staff confidence to give CSL2 declaration & & $x 2$ & & & & & \\
\hline \multicolumn{8}{|l|}{ Limit calls to Control (even loading) } \\
\hline Better forecasting of medium-term potential consequences & & & & & $x 4$ & $x 2$ & $\times 2(+1$ good) \\
\hline Mitigate criticality of incident timing (resourcing) & & $x 3$ & & & $x 2$ & & \\
\hline \multicolumn{8}{|l|}{$\begin{array}{l}\text { Increase number of limited alternatives (including disruption on } \\
\text { other services) }\end{array}$} \\
\hline More information availability to customers & $x 2$ & & & & $x 2$ & $x 3$ & $x 3$ \\
\hline Increase knowledge about geographic criticality of incidents & & & & & & $x 2$ & \\
\hline Enhanced co-ordination of response & & & & & & $x 2$ & \\
\hline \multicolumn{8}{|l|}{$\begin{array}{l}\text { Better manage extending timeframe and escalating problems / } \\
\text { difficulty }\end{array}$} \\
\hline $\begin{array}{l}\text { Better manage information overload (comprehension and } \\
\text { communication) }\end{array}$ & & & & & & & \\
\hline
\end{tabular}


Key to cells: Green = predominantly good. Red = predominantly weak. Frequencies (e.g. x2) show where systemic success factor occurred more than once. 


\section{LEARNING ABOUT THE PIDD SYSTEM - "HOW" TO GAMIFY}

While Table 1 shows a repertory of 'what' systemic success factors need to be addressed by a gamified capability to improve the PIDD system, a gamified capability for learning about the PIDD management process should also consider "how" gamification could be done. We propose that a gamified approach should:

- allow disruptions to be worked through in a safe environment and use a timelined scenario;

- build understanding about a specific scenario;

- use a systemic process of some kind to represent the systemic success factors within the PIDD system; and

- facilitate interaction between frontline staff and passengers.

Particular attention should be given to the following aspects of "how' a gamified approach could work.

\subsection{Develop heuristic decision-making}

The nature of the PIDD system means that limited opportunities exist to see how incidents develop over the medium-to-long term, especially as they become unforeseeably and increasingly extended (Törnquist, 2007) and are often overwhelmingly combinatorically complex. However, "Disruption Solvers" are always under great pressure to solve problems more quickly and effectively, so it is useful to have heuristic rules and guidelines to aid cognition.

We have found from this study that there is an intuitive and critical one-to-two hour "pacification window" within which "minor" incidents can be rectified, as passengers are willing to tolerate delay to some extent before normal services resume. But beyond two hours, as experienced in more "major" incidents, passengers no longer seem prepared to wait and want viable alternatives arrangements to be made. Beyond two hours, staff can also become compromised by legal working-time directives which have knock-on effects to the next shift and next peak demand period. Likewise, rolling-stock and engines also become too displaced for normal operations to resume without significantly re-planning rail services. As more major incidents are likely to increase the involvement of external agencies in the latter react and recovery phases of MPRR, use of shared ideals and group-based heuristics becomes more significant.

We recommend that any gamified PIDD learning environment should improve heuristic decision making to give "Disruption Solvers", especially in group-based scenarios, a means to record and reflect upon systemic success factors which are too complex to be fully considered during the unfolding of an actual disruption. The 
challenge is that "Disruption Solvers" need to capture and understand the cloud of evaporating problems created by an incident. The problem for learning about this cloud is that it only exists during a disruption, and, once the disruption has been solved and normal service resumes, the cloud of problems vanishes along with any associated learning opportunities. This study has captured some of the systemic success factors by using a mixture of incident timelines (as in Section 4) and holonic thinking (as shown in Fig. 2). This study recommends that other gamification developers should do something similar.

\subsection{Perform reviews of analysis}

The impact of practice, both weak and good, should be recorded in an accessible format on an incident-by-incident basis using operational data (e.g. Passenger Information Surveys). Reviews of practice across all incident types should also be conducted periodically (e.g. monthly or quarterly) to detect preventable reoccurrences and identify areas of potential improvement. This research showed that good practice is achievable in almost all systemic success factors but was hampered by inconsistency. Reviews should aim to embed a culture of continuous improvement in the organisation that involves operational frontline staff, passengers and senior management and recognise and reward those accordingly for positive action.

We recommend that a gamified PIDD learning environment should have periodic meetings instigated where incidences are played out (i.e. gamified) to help redefine strategic priorities and improvement objectives, give guidance to operational staff and deliver a process in which TOCs can (re)define and track a PIDD management system's performance over time. Reviews could also bring in good practice from other related sectors (e.g. air traffic control, military, emergency service, logistics etc.) to reflect upon other extant emergency preparedness models.

\subsection{Standardise operating procedures}

This research revealed that some systemic success factors were well managed and others were less well managed. Thus, the potential capability exists within CR to perform MPRR to a satisfactory level-subject to standard operating procedures being known better and used more consistently.

We recommend that a gamified learning environment should facilitate reviews of standard procedures to re-approve and reinforce good practice, improve ineffective practice and determine when new practices are required. The benefit of this would be two-fold: firstly, a consistent and reliable response could be expected for disruptive incidents, and, secondly, deviations from standard procedures can be investigated in associated reviews of analysis. An examination of standard operating procedures should cover job role definitions, authority, autonomy and reporting 
hierarchy, and they should include a critique of critical systemic interfaces of other external agencies (e.g. other TOCs, NR and BTP).

\subsection{Engage staff in ongoing development}

In having defined, appropriate and clear processes for the PIDD management system, it is also necessary to ensure that all staff are capable of performing them. Such capability includes leadership of team performances in crisis situations, and individuals being able to carry out their own individual responsibilities in "normal" (CSL 1) working conditions and "disrupted" (CSL 2) working conditions. Essential and desirable skill gaps, current and future, should also be identified; this research shows that it would be beneficial for a TOC to include:

- $\quad$ more effective use of messaging systems (e.g. Tyrell)

- more effective disruption prognostics

- increased familiarity with current operating procedures

- more knowledge on critical skills (e.g. train planning and DCM succession)

- more knowledge about where staff live in proximity to their rail network's pinch-points.

We recommend that a gamified PIDD learning environment should be embedded into an on-going programme of staff development and improvement processes that address the effective use of procedures and information systems (e.g. complete and consistent messaging through Tyrell) based around incident scenarios and problembased learning approaches for typical incidents such as those featured in this paper. These steps would be ideal for succession planning with existing staff and apprenticeship / induction style training for newer staff, as well as for increasing knowledge levels in staff to be able to provide higher levels of customer service quality during disruptions (Jade et al., 2015).

\subsection{Scan for new technology}

This research revealed that information systems were not as unfit for purpose as some CR managers originally thought, as key information systems seemed to be sufficiently integrated but not utilised fully in terms of their functionality. Also, quite surprisingly, only a small number of passengers were found to use social media. For instance, Twitter was used by only $4-6 \%$ of passengers (in 2014), and, because tweets from passengers cannot be fed automatically into official CR / NR systems, the immediacy and impact of officially endorsed social media is still currently limited. However, more live feeds should be implemented as official use of social media by TOCs are likely to grow rapidly.

We recommend that a gamified PIDD learning environment should allow users to recommend new technologies to help passengers and staff become better informed 
during disruptions. To do this requires infrastructure (such as on-track wireless coverage), communication devices for drivers (such as hands-free, voice-operated systems), on-board information screens for passengers (as seen in mainland Europe), on- and off-board cameras and GPS tracking to be installed. Upgrading of location-specific messaging at stations and at frequent points of disruptions should also be considered; other similar such suggestions are made by Panou et al. (2014).

\subsection{Develop more effective customer information channels}

This research also revealed a need to increasingly focus on customers' requirements and make more information more available to passengers in real-time. However, there should be less emphasis on pushing large volumes of generic information to passengers and greater emphasis on narrow-casting messages or masscustomisation of messages based on passengers' personal requests and locations. For instance, some passengers prefer a "do-it-yourself" approach for their travel arrangements so as long as that they have access to the suitable information sources (via the Internet); this may be the most suitable approach when all TOCS are affected by the same disruption and CSL2 ticket acceptance conditions are ineffective. Other passengers may prefer TOCs to arrange their onward journeys using a more general 'any other reasonable route' approach; this is often based on TOC employees' tacit knowledge about station hinterlands, especially when a specific TOC is affected. Alternatively, other passenger types, such as First Class travellers, may prefer an automatic "get me home" facility via a mobile device application or a concierge-type service. The key point is that different options need to be provided for different types of passengers in different scenarios, rather than using a one-size-fits-all approach to messaging.

We recommend that a gamified PIDD learning environment should allow users (e.g. frontline staff) to seek advice through different types of information provision during a disruption and consider how best to take appropriate actions, and experiment to see if these should vary with different types of customer and/or with different types of disruption (similar to Abdelatif, 2015). It is also important to recognise that disruptions can be dealt with in more than one way, and, by contextualising problembased experiential learning in this way, it is likely that better quality learning will be generated than by mandating prescriptive rules for disruptions management (Kauppi et al., 2012).

\section{ABDUCTIVE RATIONALIZATION USING THE MPRR FRAMEWORK - "WHEN" TO GAMIFY}

As with any TOC, CR is part of a larger complex customer service provision system, and is often disrupted by things completely outside of their control (Vromans et al., 
2006). However, TOCs are expected to react and recover from situations within short timelines and tight constraints whilst working with many different external stakeholders.

Reaction and recovery (of MPRR) is made difficult for TOCs by having limited input into the earlier mitigation and planning of the PIDD system, as mitigation and planning fall mainly under the jurisdictions of NR and the BTP. Therefore, a third dimension of conceptual gamification specifications, in addition to "what" and "how" must be considered, and that is "when" each action should be most effectively used in MPRR, as done in a QFD level 2 type analysis (see Clegg and Tan, 2007). For similar reasons, Chu and Oetting (2013) also only focus on developing heuristic disruption programmes for the react and recovery phase of the disruption, but notably only focus only on the positioning of rolling stock in the network, as they state that modelling and optimising dynamic changes for human factors are too complex.

\subsection{Mitigation}

Mitigation includes actions such as fencing-off track to prevent incidents involving the public, and track and signalling maintenance from NR. BTP also have an active presence at accident black spots by installing CCTV and extra safety precautions. The locomotive and rolling-stock owners will also be responsible for maintaining the fleet and mitigating any associated failures. Standard operating procedures (SOPs), new technology and performance analysis reviews play important roles in defining when each act of mitigation should be undertaken.

This research recommends that forming more effective on-going working relationships with external agencies such as NR, BTP, utility providers, bus companies, transportation, police, ambulance and transport agencies should be encouraged by any gamified learning environment. At the same time, it would be helpful to prepare more suitable communication channels for consistent messaging in the initial mitigation stage of MPRR.

\subsection{Preparedness}

Much preparation activity falls under the jurisdiction of the NR with responsibility for track infrastructure. Thus, gamification requirements for preparedness of a TOC should be focused on their employees: crew scheduling (Ceder et al., 2015), frontline platform staff, passengers and supporting systems. Herein lies the scope for improvement inspired by the professional emergency services. For instance, UK emergency services will have a "Gold", "Silver" and "Bronze" command and control hierarchy (HMSO, 2013) where "Gold Command" is strategic and maintains an objective stance, and is often deliberately geographically remote from the incident. "Silver Command" (normally identified by a person donning a high-visibility silvered 
jacket) will be extra tactical resource, whose sole role it becomes to co-ordinate the disruption response and recovery. Meanwhile, "Bronze Control" will be the everyday operational manager on the ground who has an eye on trying to sustain normality during a disruption. In comparison, this study's equivalence of a "Silver Command" was ambiguous, requiring more support from appropriate technology, process, procedures and training. Silver Command has, in these cases, been ambiguously fulfilled by a group of people consisting of NR's Mobile Operations Managers (MOMs) and TOC's DCMs and SIOs liaising with CRCL, with no singularity of authority and whose use of multifarious systems to transmit messages has been too loose. This study shows that the Silver Command equivalence has been relatively nebulous, so designing purpose-made staff development has been difficult. This has contributed to passengers' dissatisfaction about service levels during disruptions.

So, unlike the full-time emergency services which have a planned "fire-break" between defined reporting hierarchy levels during disruptive events, TOCs' relatively disparate approach to disruption management creates an undesirable division between the "Disruption Identifiers" and "Disruption Solvers" (as shown in the PIDD $\mathrm{PrOH}$ model in Fig. 2) which is caused by misused information systems, and processes and procedures which are less than completely fit-for-purpose. Whilst the full-time emergency services think of "get track clear", TOCs think of "get trains moving as scheduled". In actual fact, they should both think together with more customer focus to "get passengers to where they want to be"-with the highest possible health and safety levels in mind-as quicker and safer disruption resolutions are likely to be associated with higher customer satisfaction rates.

This study recommends that a gamified learning approach for PIDD should be developed to help to prepare frontline staff for disruption and help them adopt and develop better "command and control" management for disruptions on both an individual personal basis and a systemic organisational level; these could occur within gamified company improvement initiatives.

\subsection{Responsiveness}

Responsiveness is what the full-time emergency services excel at, so, during a PIDD response, an "expert" incident response person, such as a Silver Commander, should take control to co-ordinate the extraordinary activities and report upwards to the Gold Command (in the TOC's control room). This leaves the "Bronze Manager" to focus on managing normal (i.e. CSL1) operations, allowing backfilling with extra local resource as necessary. After health and safety requirements have been fulfilled, the priority for TOCs at this stage should be to get passengers to their destinations as swiftly as possible. Ideally, all incident-related communications should go through the designated Silver Command, who should take a longer-term view on the overall recovery of the situation, which, in turn, should free up time for the Bronze Manager to be more present in frontline response activities. 
Ideally, the Silver Commander will also have two-way communications in real-time (including video) linking them with other key people across the incident response team. Silver Command will then be in a situation to give accurate estimates on recovery actions and lead-times. In between incidents, when not so busy, the Silver Commander should assist with mitigation (e.g. training) and preparedness activities and become a full-time PIDD MPRR expert. Metrics on lapsed time against estimates and observed behaviours during CSL2 should also be routinely recorded by the Silver Commander role, capturing characteristics of disruptions and their vanishing cloud of problems to inform future PIDD management systems and gamification of related learning scenarios.

Good practice shows that the source of any PIDD-related message, whether cast by Gold-, Silver- or Bronze-type roles, should be trustworthy, and the message must be informative, targeted and cast through the most effective channel used by its intended audience in a language and style that the audiences will be most receptive to. Communication to the public is a key part of any response plan by these roles and should not be left to chance, especially in cases of rail disruptions where TOC disruptions management teams are not co-located.

\subsection{Recovery}

Recovery is the most visible part of MPRR as passengers and frontline staff are inseparably involved. The recovery phase begins when the cause of a problem has been solved and has been declared as "solved" to passengers, but its effects are still being felt for an indefinite period afterwards. These CR cases also show that new systems and devices used to track the whereabouts of key resources during disruption (especially for key staff, engines, rolling-stock and infrastructure affecting the PIDD management system) would be useful, but the key to this phase's success is still likely to lie in the tacit skill and knowledge levels of frontline staff. Thus, ideally at the end of this recovery stage, the operating authority should be handed back to the Bronze (normal operations) Manager and a simultaneous "hot brief" fed back to the incident response team about key actions and performance metrics.

A gamified learning approach for PIDD should allow players to debate and play-out alternate courses of action in a group to experiment what works best for the customer as this phase is characterised by much passenger frustration. As such, the expectations of customers need to be carefully managed through constant liaison with other TOCs (in CSL2) and transport operators providing replacement services to clear the backlog of re-routed passengers; moreover, alternative routes and information should also be clearly made available to passengers. Quality and timeliness of messaging to passengers at this stage is very sensitive and closely linked to how customers perceive the quality of service and the feedback they give afterwards. 


\section{CONCLUSION}

The overall aim of the MPRR (Mitigate-Plan-React-Recover) framework in this context should be to simultaneously reduce operational costs for a train-operating company (TOC) whilst increasing its customers' satisfaction rates through better use of information by frontline staff during disruptions.

This action research project has used Canonical Action Research (CAR) to investigate systemic issues in the PIDD (Passenger Information During Disruption) management system. PrOH modelling created an initial holon of the PIDD system which was prescient in facilitating discussions in workshops about linearity (using timelines) versus systemicity (using the PrOH model) to explore systemic success factors and information-provision deficiencies inherent in the PIDD management system. Seven real-time incidents (five types) over an 18-month period were observed.

The outcomes consist of three dimensions of a conceptual design specification for a gamified learning environment to improve customer service in times of disruption. The conceptual design is defined in one dimension by the 21 systemic success factors common to all seven incidents by stating "what" should be addressed in the gamified learning capability (as summarised in the repertory template in Table 2, Section 4). In the second dimension, the conceptual design is defined by six design criteria recommendations which define "how" a gamified learning capability could address these systemic success factors (which are given in Section 5). The third conceptual design dimension is defined through abductive reasoning to the MPRR reference framework which highlights "when" actions by frontline staff are most suitably gamified (as discussed in Section 6).

Presently, opportunities for learning about PIDD management systems are limited as its "vanishing cloud" of systemic problems is only apparent at the critical periods of react and recover, and are seldom captured. Once a disruption is solved and the cloud of problems has evaporated, the associated learning opportunities are also lost; so too are the impetuses and creativity to build new learning capabilities and/or serious learning games to gamify the process to improve the PIDD system. This research has captured these parsimoniously at a conceptual level for other researchers, train operating companies and serious game developers to build upon (Tschriner et al., 2014) without oversimplifying the challenges in disruptions management (Feltovich et al., 2004). These conceptual design requirements are sensitive to socio-technical systemic problems and consider that learning capabilities and/or gamifying solutions may be technical and/or non-technical; computer-based 
and/or manual paper-based (as called for by Meijer, 2012) and may use a mix of optimisation and soft improvement measures.

The challenge now remains to develop a prototype gamified learning capability to improve the PIDD management system based on these conceptual requirements. Any such capabilities should take steps to increase the certainty and confidence of frontline staff's decision-making ability, reduce the lead-times of decision making in the PIDD management system and ultimately improve customer satisfaction rates in rail services. These steps would help meet current widespread concerns of national governments and rail regulators (EU, 2011) and improve the quality of rail services, especially during disruptions, and reduce user costs. It is hoped that these conceptual requirements will lead to the development of realistic verisimilar holistic and heuristic learning capabilities symbolic of socio-technical factors as discussed in this paper (i.e. the PIDD socio-technical system) (as per Dormans, 2011; Myers, 1999).

This study is limited as it is currently only based on findings from one train-operating company in Great Britain. However, by taking a range of typical cases, using a typical train-operating company and embedding this action research in a wider body of knowledge from rail customer service and emergency response, we believe that the proposed conceptual design requirements are transferable to other similar TOCs in other similar countries or services (e.g. bus and air travel).

\section{ACKNOWLEDGEMENTS}

Thanks to Chiltern Railways Company Ltd. (especially Rob Brighouse, Jenny Payne and Matt Bromley), London Underground Ltd., British Transport Police (BTP) and the Cabinet Office Briefing Rooms (COBR).

\section{REFERENCES}

Adbelatif, A., Rachid, C, Smain, A., Verzea, I., 2015. Promoting a sustainable organizational culture in a company: The National Railway Transport Company. Journal of Rail Transport Planning and Management. 5, 23-30.

Andreewsky, E., Bourcier, D., 2000. Abduction in language interpretation and law making. Kybernetes. 29 (7/8), 836-45.

Balfe, N., Wilson, J.R., Sharples, S., Clarke, T., 2012. Development of design principles for automated systems in transport control. Ergonomics. 55 (1), 3754. 
Belmonte, F., Schön, W., Heurley, L., Capel, R., 2011. Interdisciplinary safety analysis of complex socio-technological systems based on the functional resonance accident model: An application to railway traffic supervision. Reliability Engineering and System Safety. 96 (2), 237-249.

Caimi, G., Fuchsberger, M. Lauman, M., Lüthi, M., 2012. A model predictive control approach for discrete-time rescheduling in complex central railway station areas. Computers and Operations Research. 39, 2578-2593.

Ceder, A., Hassold, S., 2015. Applied analysis for improving rail-network operations. Journal of Rail Transport Planning and Management. 5, 50-63.

Checkland, P. B., 1981. Systems Thinking, Systems Practice. Chichester: Wiley.

Checkland, P.B., Scholes, J., 1996. Soft Systems Methodology in Action. Chichester: Wiley.

Chu, F., Oetting, A., 2013. Modelling capacity consumption considering disruption program characteristics and the transition phase to steady operations. Journal of Rail Transport Planning and Management. 3, 54-57.

Clegg, B.T., 2007. Building a holarchy using business process orientated holonic (PrOH) modeling. IEEE Systems, Man and Cybernetics: Part A. 31(1), 23-40.

Clegg, B., Shaw, D., 2008. Using process-oriented holonic (PrOH) modelling to increase understanding of information systems. Information Systems Journal. $18,447-477$.

Clegg, B., Tan, B., 2007. Using QFD for e-business planning and analysis in a microsized enterprise. International Journal of Quality \& Reliability Management. 24 (8), $813-828$.

Corman, F., D’Ariano, A., Hansen, I.A., Pacciarelli, D., 2001. Optimal multi-class rescheduling of railway traffic. Journal of Rail Transport Planning and Management. 1, 14-24.

D’Ariano, A., 2008. Improving Real-time Train Dispatching: Models, Algorithms and Applications. PhD thesis. TRAIL Research School, The Netherlands.

D'Ariano, A., Pacciarelli, D., Pranzo, M., 2008. Assessment of flexible timetables in real-time traffic management of a railway bottleneck. Transportation Research Part C. 16, 232-245. 
Deterding, S., Dixon, D., Khaled, R., Nacke, L., 2011. From game design elements to gamefulness: defining gamification. In: Proceedings of the 15th international academic MindTrek conference: Envisioning future media environments. September 2011, Tampere, Finland, pp. 9-15

DfT, Department for Transport, 2004. The Future of Rail. July 2004.

Diaz, A., Gonzalez, M.O., Gonzales-Torre, P., 1999. On-line timetable rescheduling in regional train services. Transportation Research Part B. 33, 387-398.

Dormans, J., 2011. Beyond iconic simulation. Simulation \& Gaming. 42 (5), 610-631.

Drabek, T.E., 1996. Sociology of Disaster Course Instructor Guide, Federal Emergency Management Agency (FEMA). National Emergency Training Center, Emmitsburg.

Dubois, A., Gadde, L-E., 2002. Systematic combining: an abductive approach to case research. Journal of Business Research. 55, 553-60.

Edwards, M.G., 2005. The integral holon. Journal of Organizational Change Management. 18 (3), 269-288.

Eisenhardt, K.M., 1989. Building theory from case study research. Academy of Management Review. 14(4), 532-550.

Eklund, J., 2003. An extended framework for humans, technology and organization in interaction. In: Human Factors in Organizational Design \& Management VII. IEA Press, Santa Monica, pp. 47-54.

Espinosa-Aranda, J.L., Garcia-Ródenas, R., 2013. A demand-based weighted train delay approach for rescheduling railway networks in real time. Journal of Rail Transport Planning and Management. 3, 1-13.

European Commission, 2011. Roadmap to A Single European Transport Area Towards A Competitive and Resource-Efficient Transport System. White paper on transport, Publications Office of the European Union, Luxembourg.

Farrington-Darby, T., Wilson, J.R., Norris, B.J., Clarke, T., 2006. A naturalistic study of railway controllers. Ergonomics. 9 (12-13), 1370-1394.

Feltovich, P.J., Hoffman, R.R., Woods, D., Roesler. A., 2004. Keeping it too simple: how the reductive tendency affects cognitive engineering. IEEE Intelligent Systems. 19 (3), 90-94. 
Fischer, H.W., 1998. The role of the new information technologies in emergency mitigation, planning, response and recovery. Disaster Prevention and Management: An International Journal. 7 (1), 28 - 37.

Gatto, M., Jacob, R., Peeters, L., Widmayer, P., 2009. On-line delay management on a single train line. In: Lecture Notes in Computer Science. Berlin/Heidelberg: Springer.

Glover, J., 2013. The Principles of Railway Operations. Allan Publishing Ltd. Hersham. UK.

Golightly, D., Dadashi, N., 2017. The characteristics of railway service disruption: implications for disruption management. Ergonomics, 60 (3), 307-320.

Goverde, R.M.P., Meng, L., 2011. Advanced monitoring and management information of railway operations. Journal of Rail Transport Planning and Management. 1, 69-79.

Harris, N.G., Mjøsund, C.S., Haugland, H., 2013. Improving railway performance in Norway. Journal of Rail Transport Planning and Management. 3, 172-180.

HMSO, 2013. Emergency Response and Recovery: Non-statutory guidance accompanying the Civil Contingencies Act 2004. Version 5.

Jennex, M.E., Raman, M., 2009. Knowledge management in support of crisis response. In: International Journal of Information Systems for Crisis Response and Management. 1 (3), 69-84.

Kauppi, A., Wikström, J., Sandblad, B., Andersson, A.W., 2006. Future train traffic control: control by re-planning. Cognition, Technology and Work. 8, 50-56.

Keating, E., Oliva, R., Repenning, N., Rockart, S., Sterman, J., 1999. Overcoming the Improvement paradox. European Management Journal. 17 (2), 120-134.

King, N., 2004. Using templates in the thematic analysis of texts. In Cassell, C. Symon, G. (Eds.), Essential Guide to Qualitative Methods in Organizational Research. Sage, London. 256-270.

Kirkeby, O.F., 1990. Abduktion. In: Andersen, H. (Ed.), Vetenskapsteori och metodlara. Introduktion, Studentlitteratur, Lund. Translated from Danish by Carl G. Liungman. ISBN 9789144385716

Koestler, A., 1967. The Ghost in the Machine. Arkana, London. 
Kraseman, J.T., 2012. Design of an effective algorithm for fast response to the rescheduling of railway traffic during disturbances. Transport Research Part C, 62-78.

Lamma, E., Mello, P., Milano, M., Riguzzi, F., 1999. Integrating induction and abduction in logic programming. Information Sciences. 116, 25-54.

Liebchena, C., Schachtebeck, M., Schobel, A., Stiller, S., André, P., 2010 Computing delay resistant railway timetables. Computers and Operations Research. 37 (5), 857-868.

Luéthi, M., Nash, A., Weidmann, U., Laube, F., Wüst, R., 2007. Increasing railway capacity and reliability through integrated real-time rescheduling. In: 11th World Conference on Transportation Research. Berkeley.

Meijer, S., 2012. Introducing gaming in the Dutch railways. Procedia - Social and Behavioural Sciences, 48, 41-51.

Myers, D., 1999. Simulation as play: A semiotic analysis. Simulation \& Gaming. 30 (2), 147-162.

Narayanaswami, S., Rangara, N., 2012. Modelling disruptions and resolving conflicts optimally in a railway schedule. Computers in Industrial Engineering. 64, 469481.

Panou, K. Tzieropoulos, P., Emery, D., 2013. Railway driver advice systems: evaluation of methods, tools and systems. Journal of Rail Transport Planning and Management. 3, 150-162.

Park, T., Kim, K-J., 1998. Determining an optimal set of design requirements using house of quality. Journal of Operations Management. 16 (5), 569-581.

Passenger Focus, 2014. Rail passengers' priorities for improvements https://www.transportfocus.org.uk/research-publications/publications/railpassengers-priorities-for-improvements-october-2014/ (accessed 22 June 2017)

Pender, B., Currie, G., Delbosc, A., Shiwakoti, N., 2012. Planning for the unplanned: an international review of current approaches to service disruption management of railways. In: Australasian Transport Research Forum (ATRF), 35th. Perth. 
Radhika, J., Molková, T., Martin, K., 2015. Role of railways in empowering travelers: a case study from the Czech Republic. Journal of Rail Transport Planning and Management. 5, 31-49.

Rail Delivery Group. 2015. www.raildeliverygroup.com

RSSB and TSLG, 2012. The future railway: the industry's rail technical strategy 2012. https://www.rssb.co.uk/library/future\%20railway/innovation-in-rail-railtechnical-strategy-2012.pdf (accessed 22 June 2017)

Spens, K.M., Kovács, G., 2006. A content analysis of research approaches in logistics research. International Journal of Physical Distribution \& Logistics Management. 36 (5), $374-390$.

Susman, G.L., Evered, R.D., 1978. An assessment of the scientific merits of action research. Administrative Science Quarterly. 23 (4), 582 - 603.

Törnquist, J., 2007. Railway traffic disturbance management - an experimental analysis of disturbance complexity, management objectives and limitations in planning horizon. Transportation Research Part A. 41, 249-266.

Törnquist, J., Persson, J.A., 2007. N-tracked railway traffic re-scheduling during disturbances. Transportation Research Part B, 342-362.

Tschirner, S. Sandblad, B., Andersson, A.W., 2014. Solutions to the problem of inconsistent plans in railway traffic operation. Journal of Rail Transport Planning and Management. 4, 87-97.

van Lankveld, G., Sehic, E., Lo, J.C., Meijer, S.A., 2017. Assessing gaming simulation validity for training traffic controllers. Simulation and Gaming. 48 (2), 219-235.

Voss, C., 2009. Case research in operations management. In: Karlsson, K. (Ed.) Researching Operations Management. Routledge, New York, NY. pp. 162195.

Vromans, M.J.C.M. Dekker, R., Kroon, L.G., 2006. Reliability and heterogeneity of railway services. European Journal of Operational Research. 172, 647-665.

Vansteenwegen, P., van Oudheusden D., 2006. Developing railway timetables which guarantee a better service. European Journal of Operational Research, 173, 337-350. 
Wilson, J.R., Jackson, S., Nichols, S., 2003. Cognitive work investigation and design in practice: the influence of social context and social work artefacts. In: Hollnagel, E. (Ed.), Handbook of Cognitive Task Design, Lawrence Erlbaum Associates, Publishers. 83-98

Wilson, J.R., Norris, B.J., 2006. Human factors in support of a successful railway: a review. Cognition, Technology and Work. 8 (1), 4-14.

Wüst, R., Laube, F., Roos, S., Caimi, G., 2008. Sustainable global service intention as objective for controlling railway network operations in real time. In: Proceedings of the 8th World Congress of Railway Research (WCRR). Seoul, Korea.

Yin, R., 1994. Case Study Research. Sage Publications. Beverley Hills, CA

Yoko, T., Norio, T., 2005. Robustness indices for train rescheduling. In: $1^{\text {st }}$ International Seminar on Railway Operations Modelling and Analysis. Delft, The Netherlands. 


\section{Appendix 1: Map of CR's network}

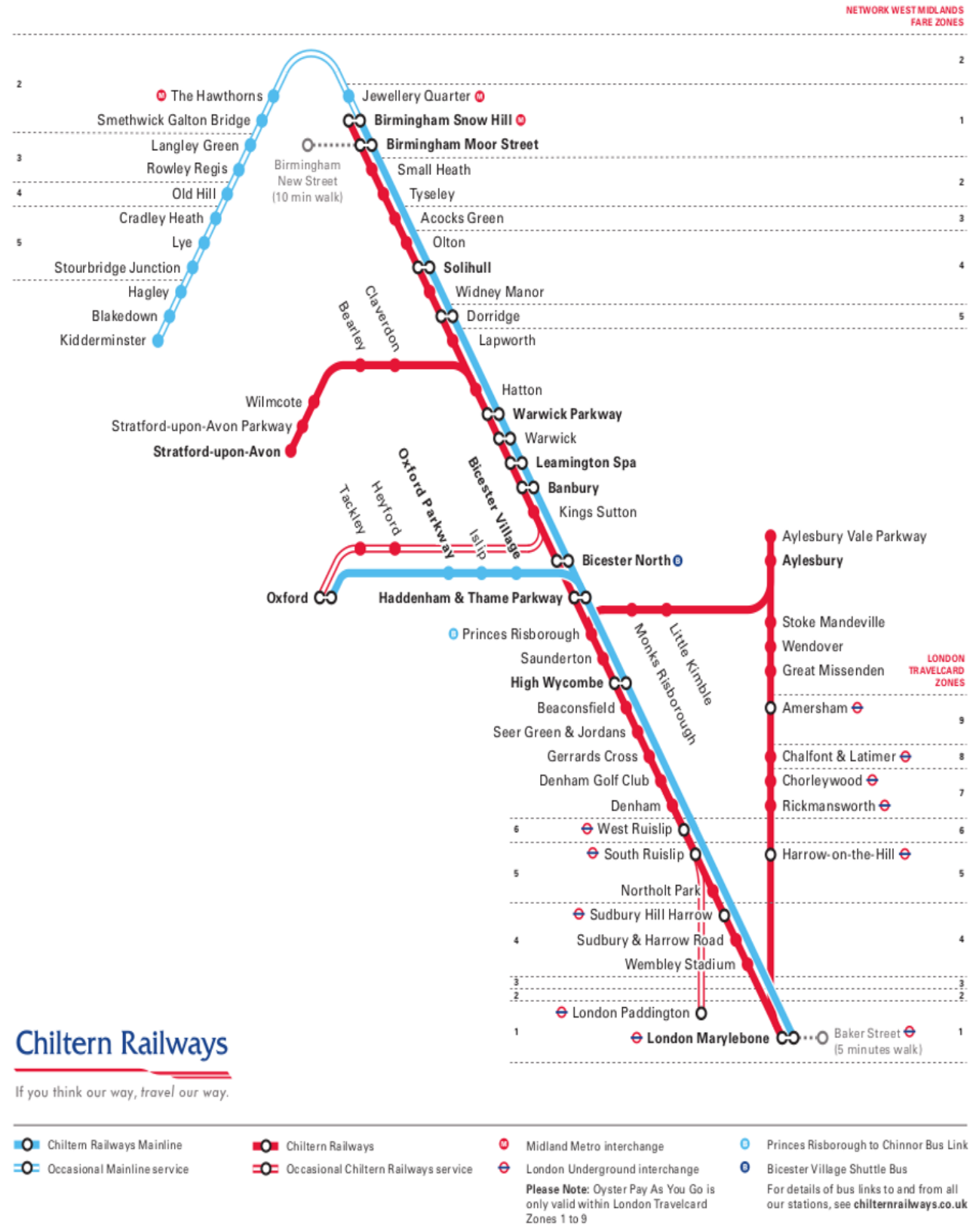




\section{Appendix 2: Glossary of Rail-Specific Terms}

\begin{tabular}{|c|c|}
\hline Key Term & Definition / Brief Explanation \\
\hline AMS & Station code for Amersham \\
\hline Area Director & $\begin{array}{l}\text { A Network Rail role in charge of a large geographical area of rail } \\
\text { network }\end{array}$ \\
\hline ATP & Automatic Train Protection \\
\hline Aynho Junction & $\begin{array}{l}\text { A rail junction between Banbury and High Wycombe (Aynho is just } \\
\text { south of Banbury Station) }\end{array}$ \\
\hline BAN & Station code for Banbury \\
\hline BCS & Station code for Bicester North \\
\hline Black Service & No trains running on a region of the rail network \\
\hline British Transport Police (BTP) & An independent police force for the whole network \\
\hline Control log & Records of incidents and actions \\
\hline CRCL & Chiltern Railways Company Ltd. \\
\hline $\begin{array}{l}\text { Crew / Train Crew / on board } \\
\text { train crew }\end{array}$ & Train-operating employees on board trains \\
\hline CSL1 (Green / Yellow Service) & Normal undisrupted service or very minor disruptions \\
\hline CSL2 (Red Service) & Major disruptions which cause noticeable delays for passengers \\
\hline DARWIN & $\begin{array}{l}\text { A Network Rail information system used to plan and schedule all } \\
\text { train-operating companies' operations }\end{array}$ \\
\hline $\begin{array}{l}\text { DfT - Department for } \\
\text { Transport }\end{array}$ & $\begin{array}{l}\text { A UK government department responsible for travel policy and } \\
\text { safety }\end{array}$ \\
\hline Duty Control Manager (DCM) & $\begin{array}{l}\text { A train-operating company manager in charge of a particular shift of } \\
\text { operation. Sometimes known as Route Control Manager. }\end{array}$ \\
\hline Duty Fleet Manager / DFM & $\begin{array}{l}\text { A train-operating company manager in charge of engines and rolling } \\
\text { stock (planning thereof) }\end{array}$ \\
\hline Drivers / Train Drivers & Train-operating company employees who drive trains \\
\hline EUS & Station code for Euston (London) \\
\hline FGW & First Great Western-a train-operating company \\
\hline Frontline platform staff & $\begin{array}{l}\text { Train-operating company staff who deal with customers-on trains } \\
\text { and off trains }\end{array}$ \\
\hline JASMIN & $\begin{array}{l}\text { A supplier of information systems to railway companies-in this case } \\
\text { passenger information systems }\end{array}$ \\
\hline $\mathrm{HOH}$ & Station code for Harrow-on-the-Hill \\
\hline HWY & Station code for High Wycombe \\
\hline IC & Incident Controller \\
\hline Kelnform+ & A customer information system provided by KeTech \\
\hline LM & London Midland-a train operation company \\
\hline LMS & Station code for Leamington Spa \\
\hline LOROL & London Overground Rail Operations Ltd. A train Operating Company \\
\hline LUL & London Underground Ltd. \\
\hline Maintenance & Train-operating employees who fix and maintain trains \\
\hline MET & Metropolitan Line-London Underground Ltd. \\
\hline $\begin{array}{l}\text { Mobile Operations Managers } \\
\text { - MOMs - Network Rail }\end{array}$ & $\begin{array}{l}\text { Network Rail employees who resolve disruptive incidents especially } \\
\text { those concerning safety, track and signalling }\end{array}$ \\
\hline MoD & Ministry of Defence (UK Government) \\
\hline MYB & Station code for Marylebone (London) \\
\hline Network Rail / NR & A quango that operates the UK rail network \\
\hline NRE & $\begin{array}{l}\text { Network Rail Enquiries-customer website that provides rail } \\
\text { information and other customer services }\end{array}$ \\
\hline NRCC & Network Rail Communications Centre \\
\hline NWR & Normal working resumed \\
\hline OIS & Operational Information System \\
\hline On-Call Network Rail Staff & $\begin{array}{l}\text { Staff not at work but who can be called on for extra support during a } \\
\text { disruption }\end{array}$ \\
\hline On-Call Managers & $\begin{array}{l}\text { Train-operating company staff not at work but who can be called on } \\
\text { for extra support during a disruption }\end{array}$ \\
\hline
\end{tabular}




\begin{tabular}{|c|c|}
\hline Other TOCs & Other train-operating companies in GB who operate franchises \\
\hline OTM & On the move \\
\hline $\begin{array}{l}\text { Passenger Service Director / } \\
\text { Customer Service Director }\end{array}$ & $\begin{array}{l}\text { A train-operating company senior manager responsible for } \\
\text { passenger service }\end{array}$ \\
\hline PIDD & Passenger information during disruption \\
\hline Points clipped & Points physically held secure \\
\hline PRR & Station code for Princes Risborough \\
\hline Route Control messages & Message sent by the Route Control Manager \\
\hline $\begin{array}{l}\text { Rail, Maritime and Transport } \\
\text { (RMT) Union }\end{array}$ & A trade union representing rail workers in the UK \\
\hline Route Control Manager & $\begin{array}{l}\text { A train-operating company manager in charge of a part of a network. } \\
\text { Sometimes known as a Duty Control Manager. }\end{array}$ \\
\hline S\&T & Signalling and Track (maintenance) \\
\hline Signal Controller / Signaller & A Network Rail employee who controls track signals \\
\hline SPAD & Signal Passed At Danger \\
\hline RDG & Rail Delivery Group_a government working group \\
\hline RSSB & $\begin{array}{l}\text { Rail Systems and Safety Board for the UK-a government body } \\
\text { tasked to improve overall rail service }\end{array}$ \\
\hline RTS & $\begin{array}{l}\text { Rail Technical Strategy—produced by the Rail Delivery Group } \\
\text { (RDG) }\end{array}$ \\
\hline $\mathrm{SIO}$ & Senior Incident Officer-the senior person at an incident \\
\hline Social Media Manager & $\begin{array}{l}\text { Member of the train operating company responsible for social media } \\
\text { (such as Facebook and Twitter) }\end{array}$ \\
\hline $\begin{array}{l}\text { Service Information Controller } \\
\text { (SIC) }\end{array}$ & $\begin{array}{l}\text { A train-operating company employee responsible for communication } \\
\text { generated on behalf of the Duty Control Manager }\end{array}$ \\
\hline $\begin{array}{l}\text { Station Manager / Duty Station } \\
\text { Manager (DSM) }\end{array}$ & A train-operating company employee in charge of a station (per shift) \\
\hline TBW & $\begin{array}{l}\text { Temporary Block Working, a method of safe working employed } \\
\text { when the signalling system is not operational }\end{array}$ \\
\hline TMIS & $\begin{array}{l}\text { Real-time information system providing information on train position } \\
\text { (by track sector) }\end{array}$ \\
\hline Train Manager & A train-operating company employee in charge of the train crew \\
\hline Train Schedule Planner & $\begin{array}{l}\text { A train-operating company employee who works with Network Rail } \\
\text { to produce rail schedule timetables }\end{array}$ \\
\hline TSLG & $\begin{array}{l}\text { Technical Strategy Leadership Group-a cross-industry body of } \\
\text { experts tasked to improve rail services-part of the RSSB }\end{array}$ \\
\hline Tyrell & $\begin{array}{l}\text { An industry messaging system used by train-operating companies to } \\
\text { communicate-internally and externally-about disruptions and to } \\
\text { other customer information platforms. Provided by Nexus Alpha }\end{array}$ \\
\hline TOC & A train-operating company \\
\hline VT / Virgin & Virgin Trains-a train-operating company \\
\hline Wembley LMD depot & Wembley London Maintenance Depot \\
\hline $\mathrm{XC}$ & Cross Country-a train-operating company in the Arriva Group \\
\hline
\end{tabular}

